\title{
The Influence of Hybrid Surface Modification on the Selected Properties of CP Titanium Grade II Manufactured by Selective Laser Melting
}

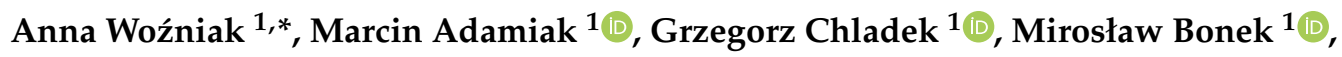 \\ Witold Walke ${ }^{2}$ (D) and Oktawian Bialas ${ }^{1}$ (D) \\ 1 Faculty of Mechanical Engineering, Department of Materials Engineering and Biomaterials, \\ Silesian University of Technology, Konarskiego 18A Street, 44-100 Gliwice, Poland; \\ marcin.adamiak@polsl.pl (M.A.); grzegorz.chladek@polsl.pl (G.C.); miroslaw.bonek@polsl.pl (M.B.); \\ oktawian.bialas@polsl.pl (O.B.) \\ 2 Faculty of Biomedical Engineering, Department of Biomaterials and Medical Devices Engineering, \\ Silesian University of Technology, Ul. Roosevelta 40 Street, 41-800 Zabrze, Poland; witold.walke@polsl.pl \\ * Correspondence: anna.wozniak@polsl.pl; Tel.: +48-32-2372603
}

Received: 22 May 2020; Accepted: 22 June 2020; Published: 24 June 2020

\begin{abstract}
The human body is an extremely aggressive environment in terms of corrosion. Titanium and its alloys are one of the most popular biomaterials used for implant applications due to biocompatibility. However, every element introduced into the body is treated as a foreign body. The human body's immune response may, therefore, lead to implant rejection and the need for reoperation. For this purpose, it seems important to carry out surface modifications by applying coatings and inter alia by texturing to implants. The objective of this paper is to investigate the effect of surface treatment on the chosen properties of the pure titanium (Grade II) samples obtained by selective laser melting (SLM) processing. The samples were divided into five groups: Initial state (after polishing), after surface modification by the physical vapour deposition (PVD) method-CrN and TiN coatings were deposited on the surface of the tested material, and after laser texturing. The paper presents the results of the microscopic investigation, chemical and phase compositions, and physicochemical and electrochemical properties of the tested samples. Based on the results obtained it can be concluded that the hybrid surface modification shows significant effects on the properties of the pure titanium. The samples with the textured PVD-deposited TiN coatings were characterized by favorable physicochemical properties and were the highest performing in terms of pitting corrosion resistance.
\end{abstract}

Keywords: SLM; Ti Grade II; corrosion test; PVD (Physical Vapour Depositions) coatings; laser texturing; wettability; EIS test

\section{Introduction}

Titanium and its alloys, especially pure titanium (Ti Grade II and Ti Grade IV) and Ti-6Al-4V alloy (Ti Grade V) are the most common metallic biomaterials for long-lasting implantation in dental and orthopedic application [1,2]. Increasing employment of titanium results from its fair biocompatibility, good corrosion resistance associated with the ability to spontaneously form a passive layer and high strength-to-density ratio [3-9]. However, the passive layer does not fully guarantee corrosion protection, because it can include some defects (inclusions and discontinuity-weak spots), which could become the initial areas of corrosion [10]. This is an important aspect, given that the human body environment is an aggressive corrosive environment. Additionally, the main disadvantage of titanium is poor wear resistance, which is generally inferior to that other metallic biomaterials [11]. 
It may lead to degradation of the surface thereby releasing and accumulating elements/corrosion products causing a metallosis [11]. Salem et al. [12] suggested that titanium implants components lead to more metallosis causes in comparison to cobalt-chrome implants. Therefore, modifications of the surface properties of the titanium implants are still recognized as an important way to improve widely understood biocompatibility $[13,14]$. Serval chemical and physical surface modifications, e.g., chemical etching, plasma treatment, ion implantation. physical vapour deposition (PVD) and atomic layer deposition (ALD) coating deposition methods are used [10,15-19]. Among the many different types of coatings currently used for biomedical purposes, very common and relatively easy to perform are TiN and $\mathrm{CrN}$ coatings, which are designed to increase not only the corrosion resistance of pure titanium but also to changing the wetting angle $[19,20]$. Surface chemistry (i.e., wetting angle) together with its surface morphology are critical factors that could affect osseointegration [21,22], so to increase the possibility of bone tissue growth, additional methods of treatments are considered, such as laser texturing [23-27]. Some work also suggests that surface texturing could be a method to enhance tribological properties [27].

Therefore, in the presented work we focused the surface modification of titanium Grade II manufactured by selective laser melting. The choice of this material was motivated by the fact that it is the main material used for dental implants [28-30] and it is an attractive basis for lowering the Young's modulus [1-7]. Moreover, the dental implantology is also an area of potential application of using selective laser melting (SLM) technology [31,32]. The use of titanium allows also assessing the effect of treatment on the dominant component of its alloys, without an impact resulting from other components. To improve surface properties, we used the hybrid modification by the PVD method ( $\mathrm{CrN}$ and TiN coatings deposition) and laser texturing. The aim of the presented work was to instigate the influence of hybrid coating on the chosen properties, such as the value of contact angle, surface free energy (SFE), corrosion resistance and wear resistance of the Grade II pure titanium samples manufacturing by selective laser melting. The selection of the investigated aspects is related with functioning of the implants. Wetting angle and surface free energy are important factors that could affect cellular response and bacterial plaque accumulation [21,22], surface topography (roughness, micro holes and scratches) is essential to promote osseointegration [22,33,34], while corrosion resistance and wear resistance are of great importance for the durability of implants [10,35]. Additionally, in order to investigate the degradation of the coating (obtained by the PVD method or spontaneously formed as a result of contact with oxygen or after texturing process) and impart more information about the corrosion mechanism the electrochemical impedance spectroscopy (EIS) test was used [36,37]. The EIS test provides information about the corrosion kinetics and electrochemical control mechanism [38].

\section{Materials and Methods}

The Grade II pure titanium powder (KAMB Company, Warsow, Poland) with chemical composition declared by the producer (Table 1), was used to prepare test samples. The powder material was spherical in shape, with size fraction in the range from 15 to $45 \mu \mathrm{m}$ (Figure 1).

Table 1. Chemical composition of pure titanium Grade II powder used in experiment.

\begin{tabular}{cccccc}
\hline Ti & Fe & O & C & N & H \\
\hline 99.70 & 0.03 & 0.11 & 0.01 & $\leq 0.01$ & 0.02 \\
\hline
\end{tabular}




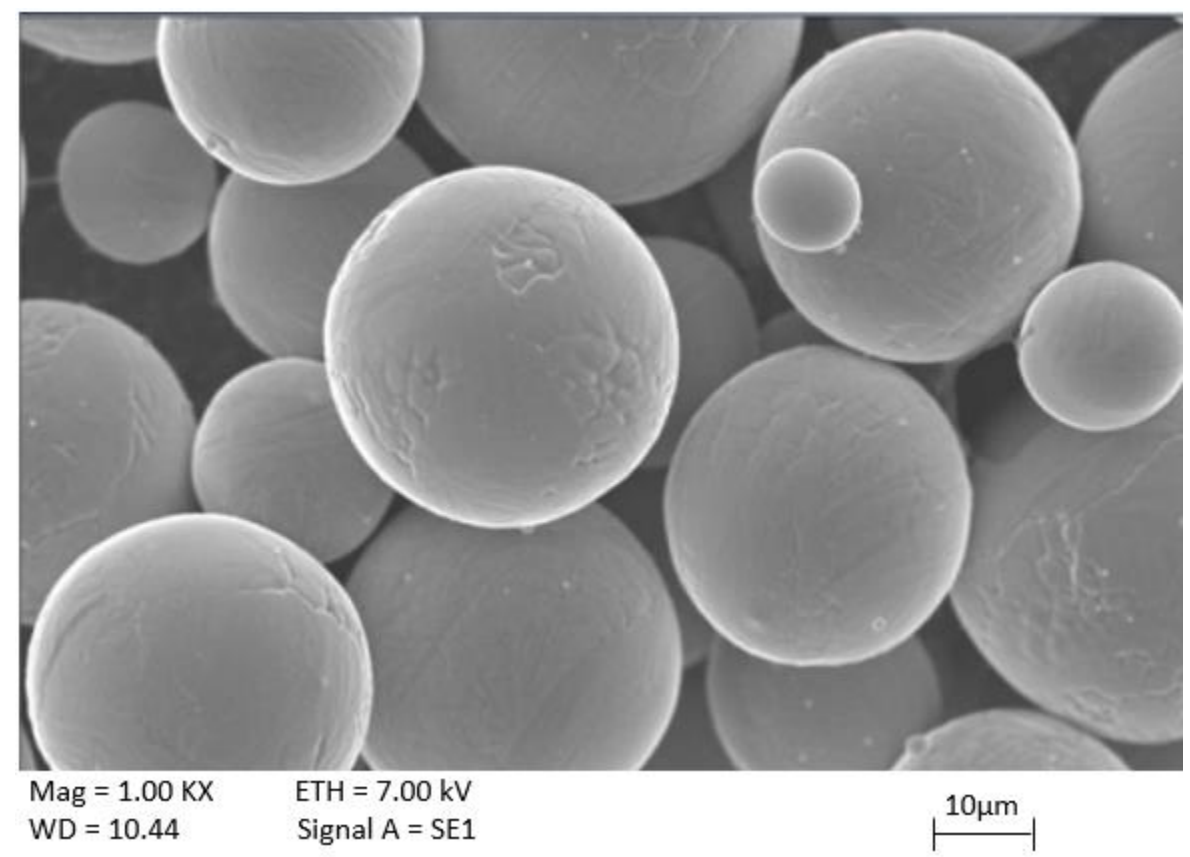

Figure 1. Scanning electron microscope (SEM) image of CP Ti Grade II powder morphology.

The tested samples were obtained by the selective laser melting process using the AM125 SLM machine (Renishaw Company, Gloucestershire, Germany). That system employs a continuous wave ytterbium fiber laser (YFL) with a wavelength of $1070 \mathrm{~nm}$ with the maximum average power $\mathrm{P}$ of $200 \mathrm{~W}$, maximum laser scanning speed SP up to $2000 \mathrm{~mm} / \mathrm{s}$, and a laser beam diameter D equal to $35 \mu \mathrm{m}$. In order to minimize the process of oxidation and degradation of the used powder material, the processes were conducted under vacuum and with the protective atmosphere of high purity argon. For this reason, the working chamber was flooded with $99.996 \%$ pure argon until the value below $0.1 \%$ of oxygen was reached. The continuous flooding with argon guarantees a low oxygen content-oxygen content of around $100 \mathrm{ppm}$ could be achieved. During the process, a pure titanium base plate was used. Before starting the process itself, the plate was subjected to polishing to guarantee good adhesion of the powder material. Additionally, the plate was heated up to $150^{\circ} \mathrm{C}$, and the temperature was kept at the same level throughout the whole process. The process technological parameters were optimized using a simplified model (Equation (1)), which specifies the density of energy input (Andrews number). According to the designation of the formula: $\mathrm{P}$-laser power [W], $\mathrm{SP}$ - scanning speed $[\mathrm{mm} / \mathrm{s}], \mathrm{t}$-layer thickness $[\mu \mathrm{m}], \mathrm{PD}$ - point distance $[\mu \mathrm{m}][39-43]$.

$$
\mathrm{E}=\mathrm{P} /(\mathrm{SP} \times \mathrm{PD} \times \mathrm{t})\left[\mathrm{J} / \mathrm{mm}^{3}\right]
$$

The energy density delivered to the powder material was approximately $75 \mathrm{~J} / \mathrm{mm}^{3}$ (Table 2). Samples selected for testing are characterized by a density above $95 \%$ of the theoretical density of pure titanium $\left(4.51 \mathrm{~g} / \mathrm{cm}^{3}\right)$-the density of the tested samples was measured according to the Archimedes buoyancy method, using type AS 220 R2 analytical balance (Radwag, Radom, Poland) with the measurement accuracy of $\pm 0.1 \mathrm{mg}$. A meander scan strategy was employed. The cubic specimens with an edge length of $10 \mathrm{~mm}$ were built at $0^{\circ}$ to the build direction. Process parameters, scan strategy, and samples' orientation were designed with MARCAM AutoFab software (PresseBox, Baden-Württemberg, Germany).

In the next stage all tested samples were subjected to mechanical grinding, which was performed using a MD-Piano disc (MD-Piano 200,600, 1200) in time $t=2$ min per each gradient of disc and mechanical polishing, which was carried out with colloidal silica suspension OP-U $0.04 \mu \mathrm{m}$ in time 
$\mathrm{t}=10 \mathrm{~min}$. The mechanical finishing process was performed using the grinding-polishing machine TERGAMIN-30 (Struers, Willich, Germany).

Table 2. Process parameters and obtained density value of test samples.

\begin{tabular}{ccc}
\hline Parameters & Value & Density of the Tested Samples $\rho,\left[\mathrm{g} / \mathrm{cm}^{3}\right]$ \\
\hline Laser power $\mathrm{P},[\mathrm{W}]$ & 200 & \\
Scanning speed $\mathrm{SP},[\mathrm{mm} / \mathrm{s}]$ & 1333 & $4.31 \pm 0.02$ \\
Layer thickness $\mathrm{t},[\mu \mathrm{m}]$ & 25 & \\
Poind Distance PD, $[\mu \mathrm{m}]$ & 80 & \\
Energy Density E, $\left[\mathrm{J} / \mathrm{mm}^{3}\right]$ & 75 & \\
\hline
\end{tabular}

In the next stage the nitride layers were deposited on the surface of the tested samples by the PVD method. The specimens were divided into two groups, depending on the type of the coating- $\mathrm{CrN}$ and TiN. The CrN coatings were deposited by the sputtering method. The thickness of the obtained CrN layer was approximately $\sim 2 \mu \mathrm{m}$. The TiN coatings were deposited by the arc evaporation method. The thickness of the obtained TiN layer was approximately $\sim 4 \mu \mathrm{m}$. The specimens in the initial state were ultrasonically cleaned in a isopropyl alcohol for $15 \mathrm{~min}$ before surface modification.

Laser micro texturing of samples with PVD coatings was performed on selected samples. The experiment was accomplished by the A-355 Laser Micromachining system (Oxford Lasers, Didcot, UK) based on $355 \mathrm{~nm}$ wavelength diode-pumped solid-state picosecond laser. The system of pulsed laser beam emission was chosen due to the potential of achieving high energy density and the ability to perform ablation, i.e., the situation in which high-energy laser radiation quantum is able to decrease the strength of the bonds between the particles which, in effect, makes it possible to evaporate atoms layer by layer. The structure modification by a pulsed laser makes it easier for an extremely focused, pulsed light beam to fall to consecutive locations where the material is evaporated, resulting in the absorption of the energy of the photon by the activated atoms and their evaporation (ablation). The maximum pulse energy for the A- 355 ps Laser Micromachining system is $0.2 \mathrm{~mJ}$ with an average power of $18 \mathrm{~mW}$, the pulse duration is in the range of $5-10 \mathrm{ps}$. The control software system is Cimita (Oxford Lasers, Didcot, UK), which enables us to create, edit and run Computerized Numerical Control (CNC) programs. The texturing process parameters were presented in Table 3. The path of laser texturing was the tightly arranged regular hexagonal honeycomb pattern with the side length of $0.29 \mathrm{~mm}$ (Figure 2) [27,44,45].

Table 3. Laser texturing process parameters.

\begin{tabular}{cccccc}
\hline Cutting Speed & Frequency & $\begin{array}{c}\text { Laser Power at } \\
\text { Laser Head }\end{array}$ & Etching Speed & Beam Width & M $^{2}$ \\
\hline $1 \mathrm{~mm} / \mathrm{s}$ & $400 \mathrm{~Hz}$ & $48 \mathrm{~mW}$ & $1 \mathrm{~mm} / \mathrm{s}$ & $\sim 30 \mu \mathrm{m}$ & $<1.2$ \\
\hline
\end{tabular}

Before testing, all samples were placed in an ultrasonic bath for $15 \mathrm{~min}$. The ultrasonic cleaning process was performed with high purity ethyl alcohol. The indication of the tested samples is given in Table 4.

Table 4. Identification of the tested samples.

\begin{tabular}{ccc}
\hline No. & Name & Surface Treatment \\
\hline 1 & M1 & Initial state \\
2 & M2 & Initial state + CrN \\
2 & M3 & Initial state + TiN \\
4 & M4 & Initial state + CrN + texturing \\
5 & M5 & Initial state + TiN + texturing \\
\hline
\end{tabular}




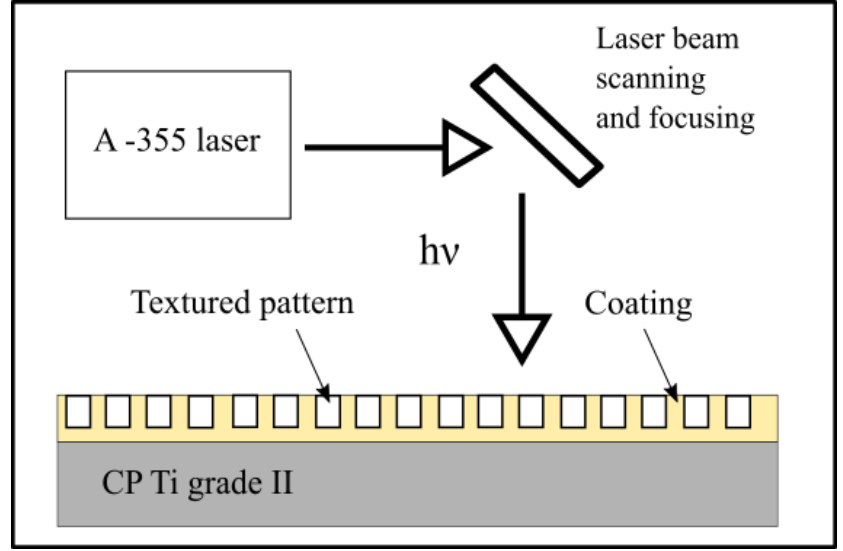

(a)

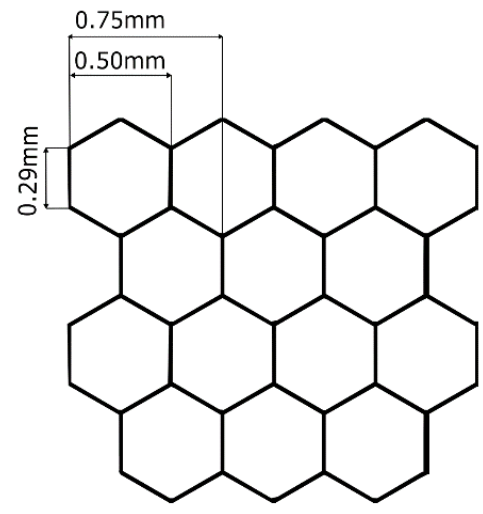

(b)

Figure 2. Schematic diagram of (a) laser micromachining system and (b) the honeycomb-like pattern of laser texturing.

\subsection{Surface Topography Investigation and Phase Analysis}

In order to obtain higher magnification images of powder material and surface topography the scanning electron microscope Supra 35 (Zeiss, Oberkochen, Germany), equipped with a SE secondary electrons-type detector was used. The microscopic observations were conducted with an accelerating voltage of $20 \mathrm{kV}$.

In order to obtain additional information of surface topography, microscopic observations using an optical microscope were performed. The microscope VHX-7000 series (Keyence, Osaka, Japan) was used.

The surface topography analysis of the tested samples using atomic force microscopy was performed. The observation was conducted by the contact mode with the use of XE-100 atomic force microscope (AFM, Park System, Mannheim Germany). For the samples M1-M3 the surface roughness measurements were also performed. The characteristic parameters describing the surface roughness - a rough mean square, $\left(R M S / R^{q}\right)$, the arithmetic average of ordinates profile $\left(R_{a}\right)$ and the sum of maximum height and maximum depth $(\Delta \mathrm{Z})$ were calculated over $25 \times 25 \mu \mathrm{m}$ area scan. The calculations were carried out using a PC computer with XEI software (Park System). For each tested sample, 20 measurements were taken.

Phase analysis studies were performed using an X'Pert PRO X-ray diffractometer (Panalytical, Almelo The Netherlands) equipped with a cobalt lamp X-ray source. The lamp was set to $40 \mathrm{kV}$ and the heater current of $30 \mathrm{~mA}$ was used. The X-ray phase analysis was carried out according to the Bragg-Brentano geometry, using PIXcel3D detector. Measurements were conducted within the $2 \Theta$ Bragg angle ranging from 20 to $90^{\circ}$ with a step of $0.05[46,47]$.

\subsection{Physicochemical and Electrochemical Properties Analysis}

Sessile drop contact angle measurements were performed on a Surftens Universal Goniometer (OEG, Frankfurt Germany) equipped with a camera for taking photos of drops of measured liquids and a PC computer with Surftens 4.5 software to analyze the recorded drop image. Distilled water (POCH S.A., Gliwice Poland) and diiodonomethane (Merck, Warsow, Poland) were used as measurement liquids, with a drop of $1 \mu \mathrm{L}$ in volume placed on the surface of the samples. After $20 \mathrm{~s}$ from when the drop was dripped the measurements were taken and the duration of one measurement was $t=$ $60 \mathrm{~s}$. The study was carried out at room temperature $\mathrm{T}=23 \pm 1{ }^{\circ} \mathrm{C}(289 \mathrm{~K})$. For all tested samples five measurements using both measurement liquids were performed, and the average value was determined. Based on the obtained values of the contact angle, the Surface Free Energy (SFE) calculation 
according the Owens-Wendt method were taken. The values of SFE and their dispersion and polar components were given in Table $5[43,48,49]$.

Table 5. The values of surface free energy (SFE) and their polar and apolar components for measuring liquids used in the Owens-Wendt method [43,48,49].

\begin{tabular}{cccc}
\hline & \multicolumn{3}{c}{$\mathrm{SFE},\left[\mathrm{m} \mathrm{J} / \mathrm{m}^{2}\right]$} \\
\cline { 2 - 4 } & $\gamma_{\mathbf{L}}$ & $\gamma_{L}^{d}$ & $\gamma_{L}^{P}$ \\
\hline Distilled water & 72.80 & 21.80 & 51.00 \\
Diiodonomethane & 50.80 & 50.80 & 0 \\
\hline
\end{tabular}

In order to determine the pitting corrosion resistance, a potentiodynamic test by recording the anodic polarization curves was performed. The pitting corrosion test was carried out according to the PN-EN ISO 10993-15 standard [50,51]. The measurements were carried out with the use of test stand comprised of an Atlas 0531 EU potentiostat (ATLAS-SOLLICH, Rębiechowo Poland), PC with AtlasLab software to saving recorded polarization curves and electrochemical cell with three-electrode system. The working electrodes were represented by the tested sample (anode), platinum wire (PtP-201) was used as an auxiliary electrode, and the reference electrode was a saturated $\mathrm{Ag} / \mathrm{AgCl}$ electrode. The corrosive tests started with the establishment of the open circuit potential $\mathrm{E}_{\mathrm{OCP}}$ at electrodes condition. Recording of the polarization curves was started from the value of the initial potential $E_{\text {init }}$ determined according the formula $\mathrm{E}_{\mathrm{init}}=\mathrm{E}_{\mathrm{cop}}-100 \mathrm{mV}$. The potential value changed along the anodic direction at $1 \mathrm{mV} / \mathrm{s}$ rate. Once the anodic current density $\mathrm{i}=1 \mathrm{~mA} / \mathrm{cm}^{2}$ or the maximum measuring range reached $+4000 \mathrm{mV}$, the polarization direction was changed. On the basis on the recorded curves, the characteristic parameters describing pitting corrosion resistance were determined-The corrosion resistance $E_{\text {corr }}[\mathrm{mV}]$, breakdown potential $E_{b}[\mathrm{mV}]$, transpassivation potential $E_{t r}[\mathrm{mV}]$ and repassivation potential $\mathrm{E}_{\mathrm{cp}}[\mathrm{mV}]$. The impedance measurements were taken with the use of AutoLab's PGSTAT 302N system (AutoLab, Warsow Poland), equipped with the frequency response analyser (FRA2) module. The tests were carried out using a three-electrode system-Identical to that used in a potentiodynamic test. This measurement system made it possible to perform tests within a $10^{4}-10^{-3}$ $\mathrm{Hz}$ frequency range. The voltage amplitude of sinusoidal signal activating amounted to $10 \mathrm{mV}$. Based on the performed tests, impedance spectra of the system were determined (Bode and Nyquist diagram) and the measurement data were compared against the equivalent system. The obtained measurement data were adjusted through the method of the smallest squares to the substitute setup and the values of resistance $\mathrm{R}$ and capacity $\mathrm{C}$ were determined. The testing environment was identical as in the pitting corrosion test. All electrochemical tests were carried out in the Ringer solution $\left(\mathrm{NaCl}-8.6 \mathrm{~g} / \mathrm{cm}^{3}\right.$, $\mathrm{KCl}-0.3 \mathrm{~g} / \mathrm{cm}^{3}, \mathrm{CaCl}_{2} 2 \mathrm{H}_{2} \mathrm{O}-0.33 \mathrm{~g} / \mathrm{cm}^{3}$ ) at the temperature $\mathrm{T}=37 \pm 1^{\circ} \mathrm{C}$ and $\mathrm{pH} 6.9 \pm 0.2$.

The microscopic observation of the surface of the tested samples before and after potentiodynamic tests was performed using an Axio Observer Z1 Microscope (Zeiss, Oberkochen, Germany).

\subsection{Wear Test}

The wear test was performed using the pin-on-disc method. The test was carried out using a CSM tribometer (CSM Instruments, Needham, MA USA), equipped with an arm with a pin holder, controller and the rotated stage. A ceramic ball $\mathrm{Al}_{2} \mathrm{O}_{3}$ with the $6 \mathrm{~mm}$ and $1300 \mathrm{HV}$ hardness dimeter was used as a counter specimen. The test was carried out with the load of $10 \mathrm{~N}$ and the linear speed was $10 \mathrm{~cm} / \mathrm{s}$. Prior to wear tests, both the tested samples and ball were ultrasonically cleaned in acetone. Based on the performed measurements, the value of the coefficient of friction $\mu$ was determined. All the tests were performed in ambient air conditions with temperature in the range of $18-22{ }^{\circ} \mathrm{C}$ and humidity an approximately $52-60 \%$. For each samples group, to guarantee the stability and accuracy of the experimental data, each test was repeated five times. The wear volume was calculated based on the cross-sectional area of the wear tracks, that were measured using a profilometer (Surtronic, 
Taylor Hobson, UK). The wear factor W was calculated according to Equation (2) [52], were V is wear volume $\left[\mathrm{m}^{3}\right], \mathrm{F}_{\mathrm{n}}$-force $[\mathrm{N}], \mathrm{S}$ - total sliding distance $[\mathrm{m}]$.

$$
\mathrm{W}=\mathrm{V} / \mathrm{F}_{\mathrm{n}} \times \mathrm{S}
$$

\section{Results}

\subsection{Surface Topography and Phase Analysis}

The samples in the initial state M1 were fabricated by the SLM method successfully. The surface of the tested samples subjected to the surface modification were homogenous and no unmelted powder particles and porosity or other defects could be seen. The mean value of the $R_{a}$ parameter for the M1 samples group, obtained by the AFM method for $25 \times 25 \mu \mathrm{m}$ was an approximately $84 \pm 14 \mathrm{~nm}$ (Table 6 ). The X-ray diffraction (XRD) patterns (Figure 3c) of samples in initial state M1 resulted in only alpha, which confirms the data contained in the material card, which was provided by the manufacturer. The scanning electron microscopy (SEM) and AFM (Figure 3) results of samples after PVD surface modification are continuous, no delamination in coating continuity was observed. Nitride layers were uniform, with no spalling and discoloration, surface was relatively smooth because the subtle scratches on the polished surface (Figure 3a) were covered by the $\mathrm{CrN}$ or TiN films (Figure 3d,g) [53]. However, there are a lot of microparticles on the surface of TiN coating, which is a common phenomenon in the arc evaporation PVD process. Additionally, it is noted that $\mathrm{CrN}$ coating, deposited by sputtering method exhibit more uniform surface morphology, without the formation of particles in the coatings. The particles on the surface of the M2 and M3 sample visible in Figure 3 can be Cr and Ti agglomerates less frequently observed for $\mathrm{CrN}$. Based on the obtained results changes in morphology of the coatings deposited can be observed, resulting in elevated surface roughness. The highest values of surface roughness parameters were obtained for the samples with $\mathrm{CrN}$ layer M2 and the mean value was $187 \pm 24 \mathrm{~nm}$. The deposited TiN layer (M3 samples group) proved to decrease the surface topography compared to the samples in the initial state Grade_is. The lowest value of surface roughness was obtained for the Grade_TiN sample group and the mean value of $R_{a}$ parameter was $42 \pm 9 \mathrm{~nm}$ (Table 6). Based on the local chemical analysis it can be concluded, that the process of the modification was properly carried out, according to the assumptions. The XRD spectrum shows that $\mathrm{CrN}$ coating and the TiN coatings (Figure 3f,i) have strong (113) and (111) preferential orientation, respectively.

Table 6. Results of AFM surface roughness measurements.

\begin{tabular}{cccccc}
\hline No. & Name & Area, $[\boldsymbol{\mu m}]$ & $\mathbf{R}_{\mathbf{a}},[\mathbf{n m}]$ & $\mathbf{R}_{\mathbf{q}}$ (RMS), $[\mathbf{n m}]$ & $\Delta \mathbf{Z}_{\mathbf{m a x},},[\mathbf{n m}]$ \\
\hline 1 & M1 & $25 \times 25$ & $84 \pm 14$ & $98 \pm 16$ & $377 \pm 98$ \\
2 & M2 & $25 \times 25$ & $187 \pm 24$ & $220 \pm 31$ & $966 \pm 105$ \\
3 & M3 & $25 \times 25$ & $42 \pm 9$ & $82 \pm 10$ & $162 \pm 20$ \\
\hline
\end{tabular}

The same textures were generated with the same laser processing parameters on both samples' groups after surface modification (Figure 4). The diameter of the dimples was very even and fitted the design well. It can be seen from Figure $4 \mathrm{~d}$ that the dimensions of the generated honeycomb were consistent with the CAD's model dimensions. The dimension of the circle inscribed for both sample groups after texturing a single hexagon was approximately $\mathrm{D}=0.475 \mathrm{~mm}$, which was comparable to the dimensions of the CAD model, where the diameter was $\mathrm{D}=0.5 \mathrm{~mm}$. Based on the microscopic investigation it can be found that grooves present typical laser induced surface structures, which were formed by the interaction of laser beam and sample surface. The textured surfaces obtained by laser ablation have been characterized as continuous groove, characterized by a non-regular explosively evaporated bottom (Figure $4 \mathrm{~b}$ ). Corrugated grooves with holes and chaotic structures especially for M4 samples group have also been observed (Figure 4c). For the M4 and M5 sample groups, this formed noticeable areas with slightly different colors, which is the effect of various oxide films 
that were formed on the surface of the treated areas. The texturing process was carried out without a protective atmosphere.

M1

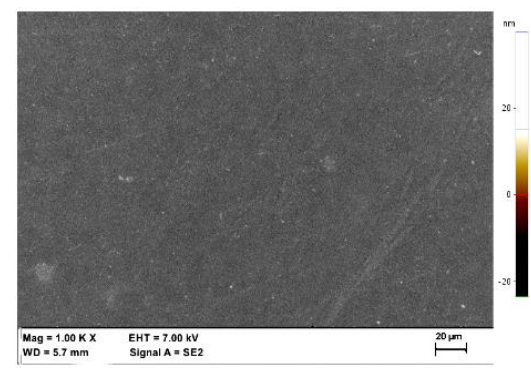

(a)

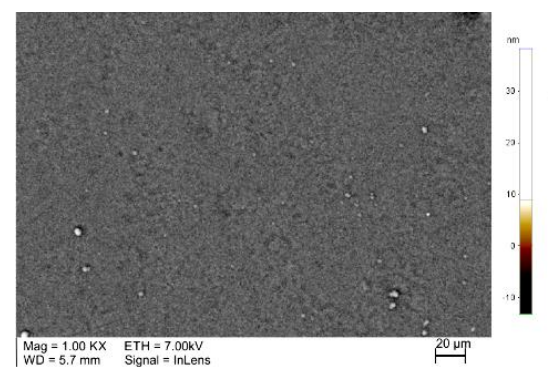

(d)

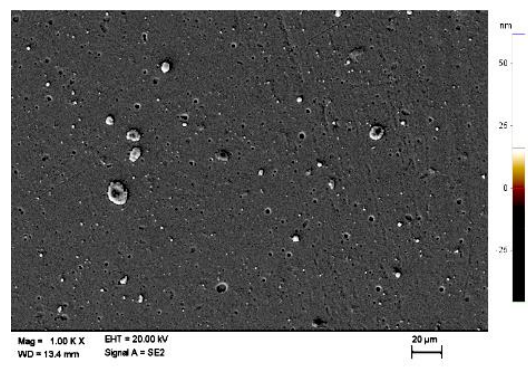

(g)

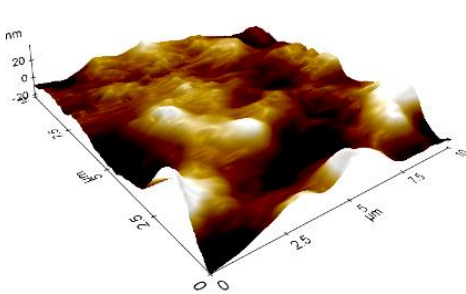

(b)

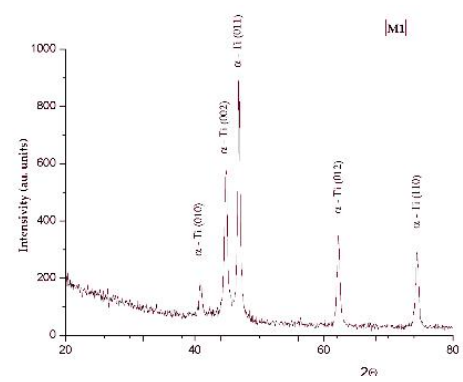

(c)

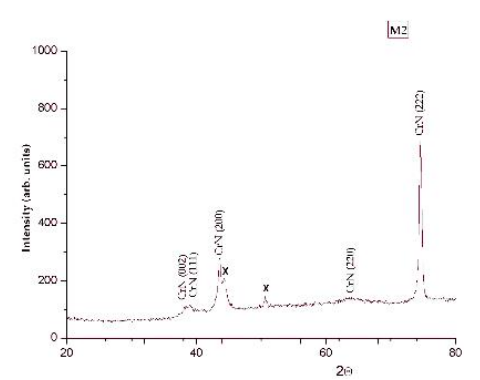

(f)

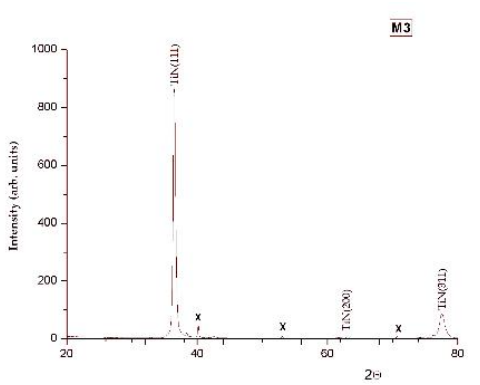

(i)

Figure 3. Images of surface topography phase composition measurements, for M1 samples group (a) SEM image; (b) atomic force microscopy (AFM) results (c) X-ray diffraction (XRD) pattern; for M2 samples group (d) SEM image; (e) AFM results (f) XRD pattern and for M3 samples group (g) SEM image; (h) AFM results (i) XRD pattern.

In the next stage the depths of the grooves of the hexagon were measured-The groove depth was measured in detail. The groove depth for the samples with $\mathrm{CrN}$ layer (M4) was approximately $1.5 \pm 0.21 \mu \mathrm{m}$ (Figure 5). The measurements were conducted using a digital microscope where it was found that the highest values of groove depth were recorded for the samples with TiN layer (M5) and the mean value was $4.5 \pm 0.15 \mu \mathrm{m}$ (Figure 6). Based on the measurements of the depth of generated textures, no thicknesses of previously refined CrN layers were exceeded, and thickness of the $\mathrm{CrN}$ layer was $\sim 2 \mu \mathrm{m}$. For a TiN layer with a thickness of approximately $\sim 4-5 \mu \mathrm{m}$, the generated texture may slightly interrupt the continuity of the layer. 


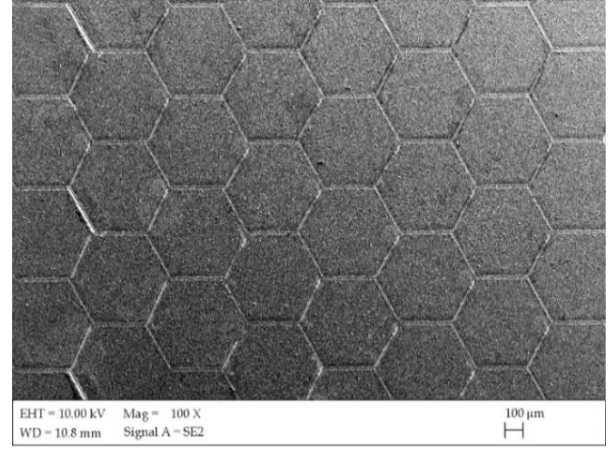

(a)

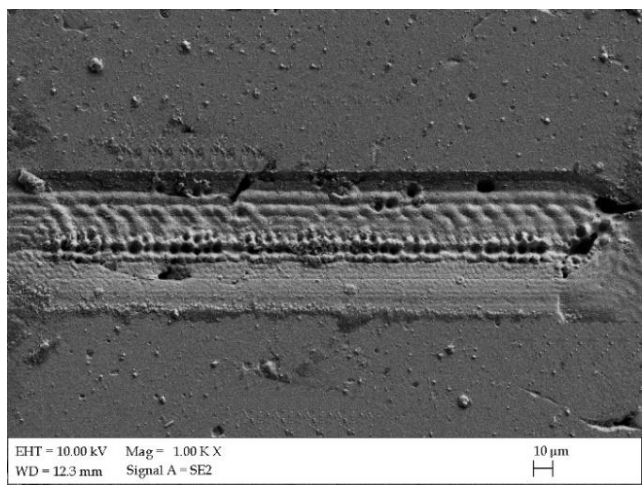

(c)

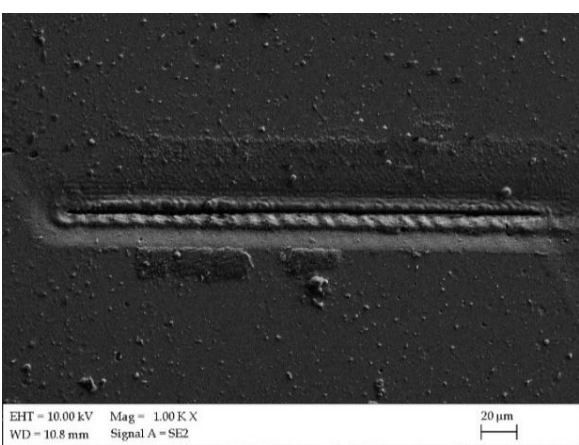

(b)

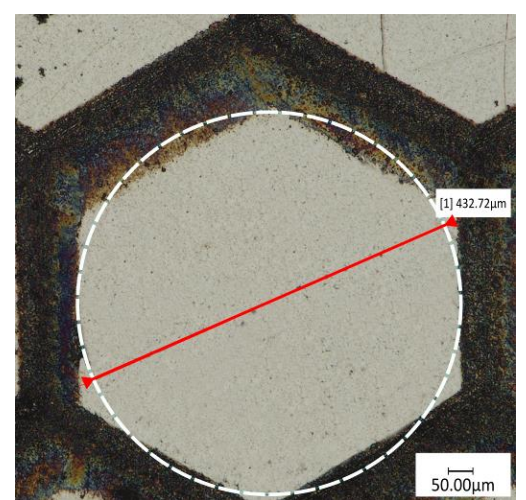

(d)

Figure 4. Examples of surface topography of the samples after texturing (a) SEM image M4; (b) SEM image single track M4; (c) SEM image single track M4; (d) optical microscopy M4.

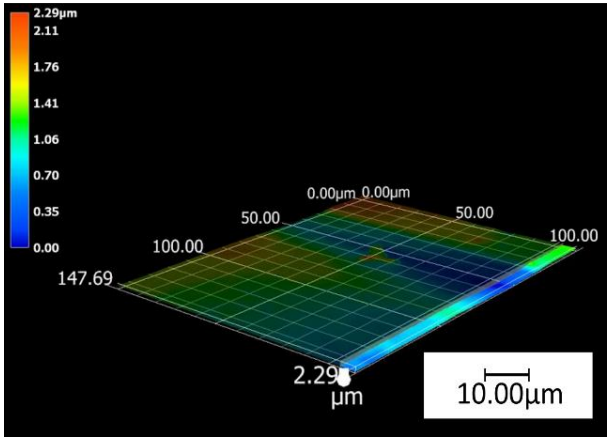

(a)

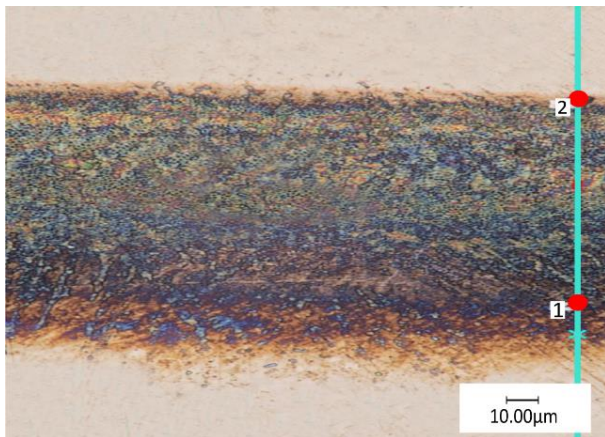

(b)

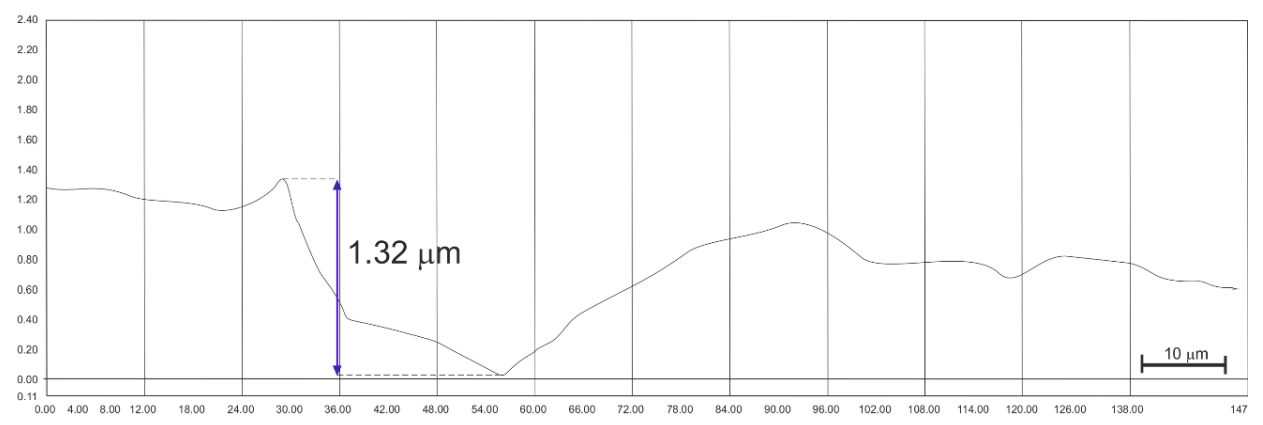

(c)

Figure 5. The results of digital microscopy observation for the 4th sample group M4: (a) 3D visualization of a single path; (b) single track with an indication of the depth measurement location; (c) groove depth measurements. 


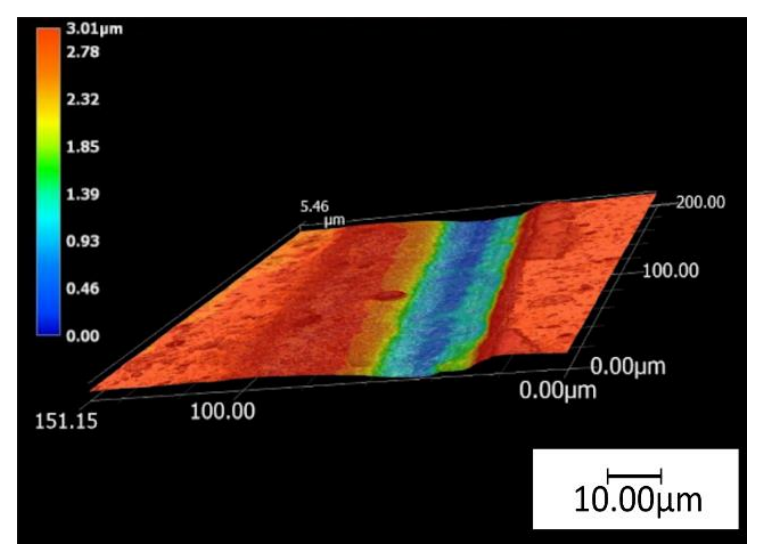

(a)

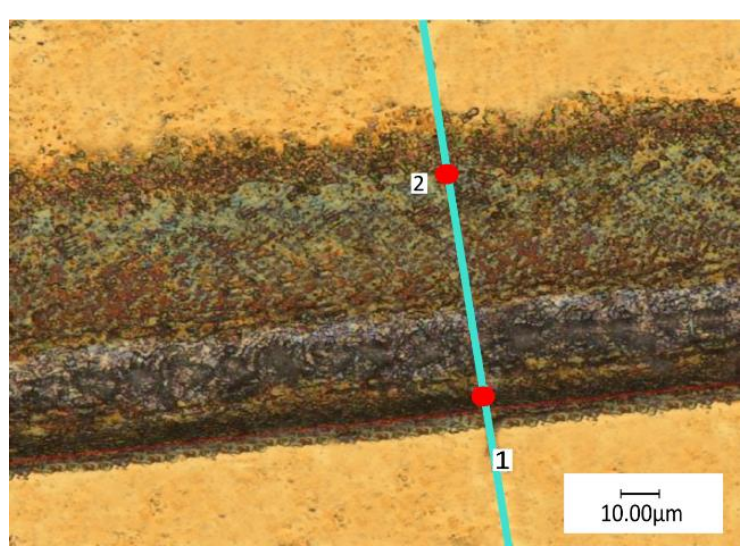

(b)

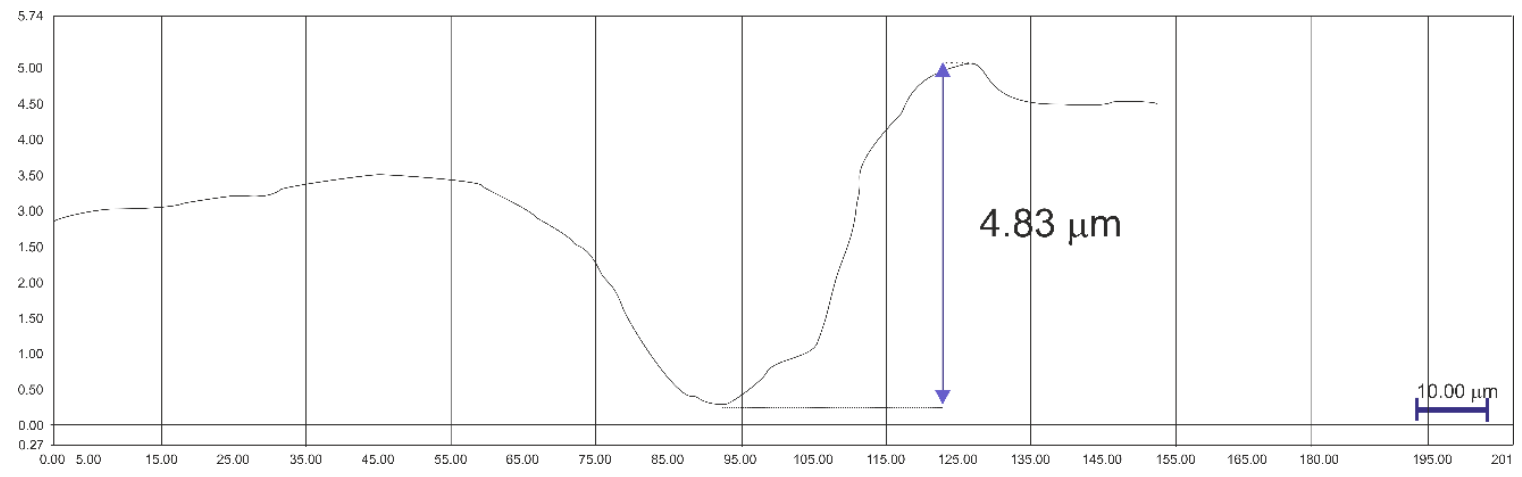

(c)

Figure 6. The results of digital microscopy observation for the sample group M5: (a) 3D visualization of a single path; (b) single track with an indication of the depth measurement location; (c) groove depth measurements.

\subsection{Physicochemical and Electrochemical Properties Analysis}

The results of wettability measurements and surface free energy calculated for all tested samples were presented in Table 7. Test examples of drops dripped on the surface of the samples are presented in Figure 7. The results obtained pointed to the increased value of wetting angle $\theta$ for the samples with PVD deposited layer and decreased for the samples after texturing the samples in initial state (M1) and the samples with CrN and TiN layer after texturing (M4, M5) were hydrophilic and showed the relative good surface wettability, with mean values for three sample groups being $\theta=78 \pm 10^{\circ}$, $\theta=79 \pm 11^{\circ}, \theta=85 \pm 11^{\circ}$, respectively. The surface modification by the PVD method effected in the elevated wetting, regardless of the type of the layer, resulting therefore in the hydrophobic surface. The highest value of contact angle was obtained for the samples with TiN layer (M3) and the mean value was approximately $\theta=101 \pm 12^{\circ}$. The wetting angle values for these sample groups obtained were $\theta_{\mathrm{av}}>90^{\circ}$. The differences were observed in the values of the surface free energy SFE throughout the investigated sample surfaces. However, values of the contact angle, using diiodonomethane as a measure liquid, were in the range from $44 \pm 6^{\circ}$ for the M5 samples group to $51 \pm 9^{\circ}$ for the M1 samples group. The values of the SFE for all tested samples were in the range of approximately $23 \mathrm{~mJ} / \mathrm{m}^{2}$ for the M3 sample group to $44 \mathrm{~mJ} / \mathrm{m}^{2}$ for the M1 sample groups. Additionally, the highest value of apolar components was higher compared to polar components. Based on this it can be concluded that all tested samples exhibited a greater affinity to apolar groups of SFE than to polar ones. 
Table 7. Results of contact angle measurements and SFE calculated.

\begin{tabular}{ccccccc}
\hline \multirow{2}{*}{ No. } & \multirow{2}{*}{ Name } & \multicolumn{2}{c}{ Wetting Angle, $\left[{ }^{\circ}\right]$} & \multicolumn{2}{c}{ Surface Free Energy, $\left[\mathbf{m} \mathbf{J} / \mathbf{m}^{\mathbf{2}}\right]$} \\
\cline { 3 - 6 } & & Distilled Water & Diiodonomethane & $\gamma_{\mathrm{S}}$ & $\gamma_{d}^{S}$ & $\gamma_{p}^{S}$ \\
\hline 1 & M1 & $78 \pm 10$ & $51 \pm 9$ & 44 & 25 & 10 \\
2 & M2 & $98 \pm 8$ & $47 \pm 10$ & 31 & 21 & 5 \\
3 & M3 & $101 \pm 12$ & $47 \pm 10$ & 33 & 17 & 4 \\
4 & M4 & $79 \pm 7$ & $45 \pm 7$ & 37 & 36 & 8 \\
5 & M5 & $85 \pm 11$ & $44 \pm 6$ & 37 & 32 & 6 \\
\hline
\end{tabular}

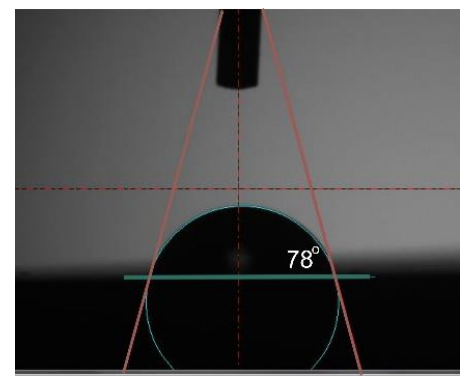

(a)

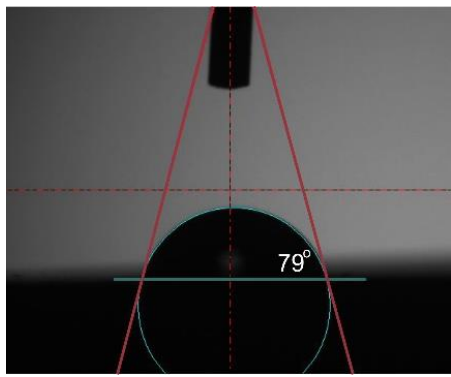

(d)

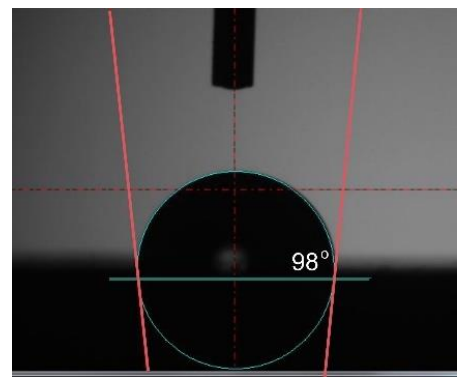

(b)

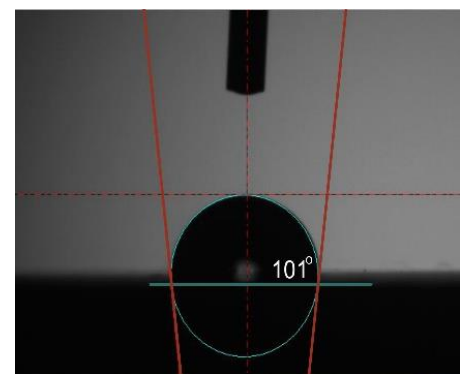

(c)

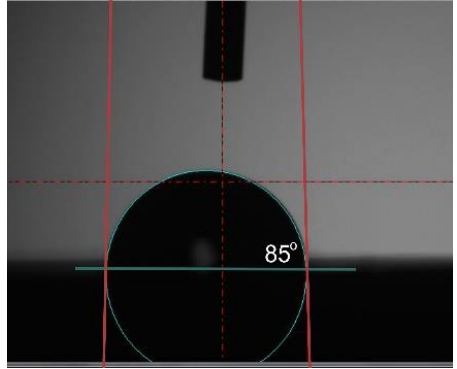

(e)

Figure 7. Sample measurement of wetting angle (a) M1; (b) M2; (c) M3; (d) M4; (e) M5.

The purpose of potentiodynamic testing was to evaluate the pitting resistance in form of anodic polarization curves shown in Figure 8. Additionally, the characteristic values describing the pitting corrosion resistance are presented in Table 8. Only for the samples in initial state M1 were the hysteresis loops recorded; the existence breakthrough potential $\mathrm{E}_{\mathrm{b}}$ and the repassivation potential $\mathrm{E}_{\mathrm{cp}}$, proving initiation and development of pitting corrosion, were measured (Figure 8). The mean values of breakdown potential and repassivation potential were $\mathrm{E}_{\mathrm{b}}=1379 \pm 87 \mathrm{mV}$ and $\mathrm{E}_{\mathrm{cp}}=1379 \pm 87 \mathrm{mV}$, respectively. For other sample groups the progress of anodic polarization curves was characteristic for the samples with high pitting corrosion resistance. The existence of the transpassivation potential has been stated. The highest value of transpassivation potential was observed for the 5 th sample group M5 (the samples with TiN layer and after texturing treatment) and the mean value was approximately $E_{\mathrm{tr}}=3052 \pm 143 \mathrm{mV}$. Similar results were observed for the samples with that same layer M3 and the average value of transpassivation potential was $E_{t r}=2572 \pm 102 \mathrm{mV}$. However, in samples with $\mathrm{CrN}$ film deposited by the PVD method, lower values of transpassivation potential were noted, regardless of the presence of the texture on the surface. The values for M2 and M4 were similar and were in the range from 1088 to $1104 \mathrm{mV}$. Additionally, the values of transpassivation potential for both sample groups with $\mathrm{CrN}$ layer were lower comparable to the value of breakdown potential established for the samples in initial state M1, which indicates lower resistance to pitting corrosion. 


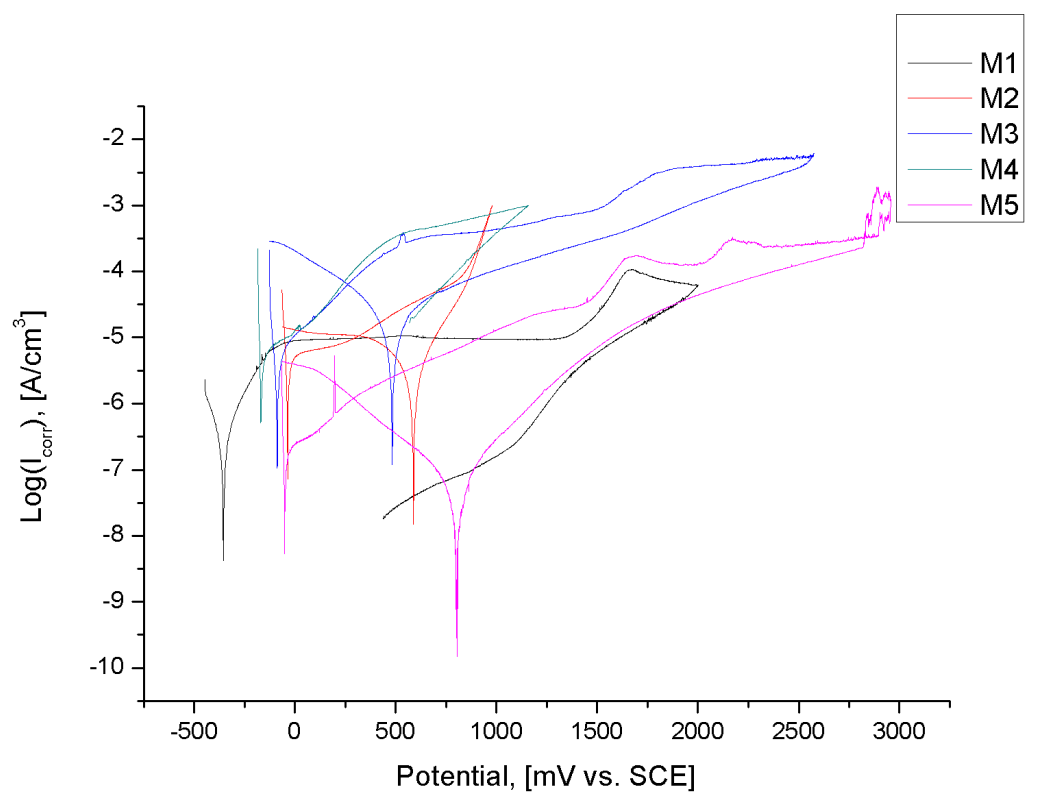

Figure 8. Example polarization curves.

Table 8. Results of pitting corrosion test-mean values and standard deviations.

\begin{tabular}{cccccc}
\hline No. & Name & $\mathbf{E}_{\text {corr, }}[\mathbf{m V}]$ & $\mathbf{E}_{\mathbf{b}},[\mathbf{m V}]$ & $\mathbf{E}_{\mathbf{c p},},[\mathbf{m V}]$ & $\mathbf{E}_{\text {tr, }},[\mathbf{m V}]$ \\
\hline 1 & M1 & $-355 \pm 52$ & $1709 \pm 87$ & $1379 \pm 87$ & - \\
2 & M2 & $-258 \pm 21$ & - & - & $1088 \pm 87$ \\
3 & M3 & $-91 \pm 14$ & - & - & $2572 \pm 102$ \\
4 & M4 & $-57 \pm 11$ & - & - & $1104 \pm 95$ \\
5 & M5 & $-43 \pm 12$ & - & - & $3052 \pm 143$ \\
\hline
\end{tabular}

During the next stage, EIS tests were carried out to evaluate the electrochemical properties and obtain additional information about corrosion resistance. The results in the form of impedance spectra for all tested samples are presented in Figure 9. The determined impedance spectra point to diversified kinetics of the corrosion processes taking place in the system-tested samples, using Ringer solution. The Nyquist diagrams for all tested samples presented fragments of semi-circles, which is typical for the thin layer (Figure $9 \mathrm{a}, \mathrm{c}, \mathrm{e}, \mathrm{g}$ ). The presented semi-circles were deformed to a different degree, in some cases from the linear relation between the components of the imaginary impedance $Z^{\prime \prime}$ and the real one $\mathrm{Z}^{\prime}$. For the samples with TiN layer and after texturing the fragments of semi-circles were placed near the beginning of the coordinate system and the biggest were observed, which pointed to better corrosion resistance compared to the other sample groups. The maximum value of phase displacement at a broad range of frequencies presented in Bode diagram (Figure $9 b, \mathrm{~d}, \mathrm{f}, \mathrm{h}$ ) for the samples in initial state $\mathrm{M} 1$ was approximately $\Theta=70^{\circ}$. Additionally, the values of the maximum value phase displacement for the samples obtained with the same layer (before and after texturing) were similar and were $\Theta=50^{\circ}$ for the samples with $\mathrm{CrN}$ (Figure 9d,g) coat and were in the range $\Theta=65-70^{\circ}$ for the samples with TiN coat (Figure 9e,h). For all sample variants, the inclinations $\log |\mathrm{Z}|$ at the whole scope of frequency change are close to -1 which indicates the capacity character of the porous layer. 


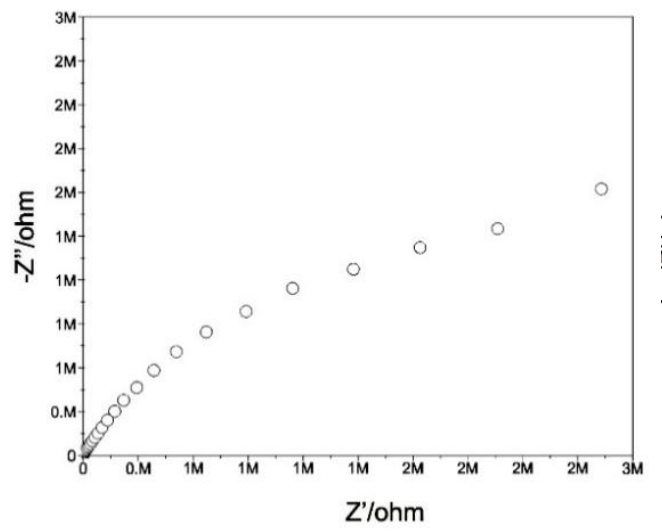

(a)

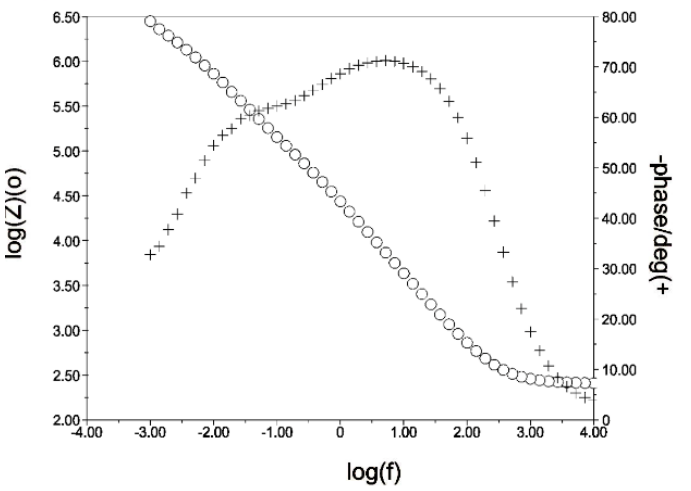

(b)

M2

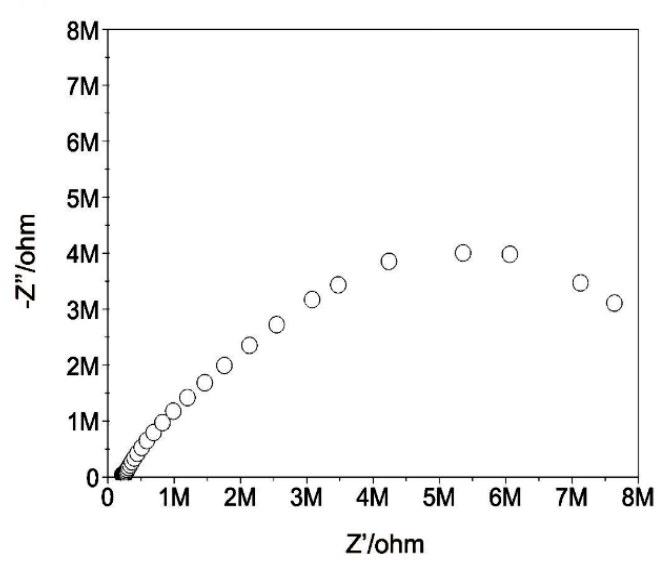

(c)

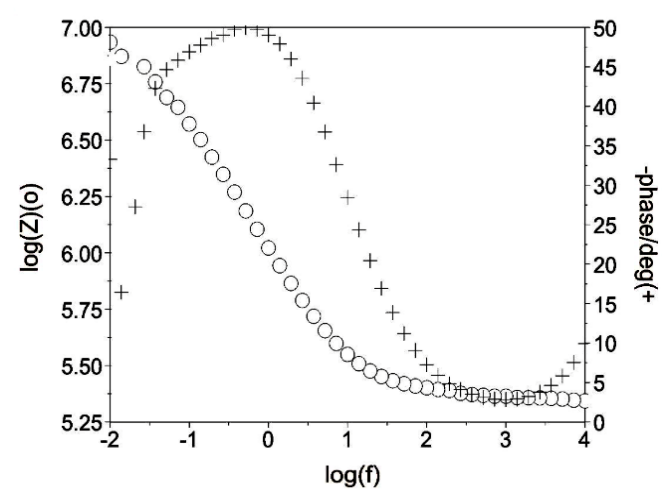

(d)

M3
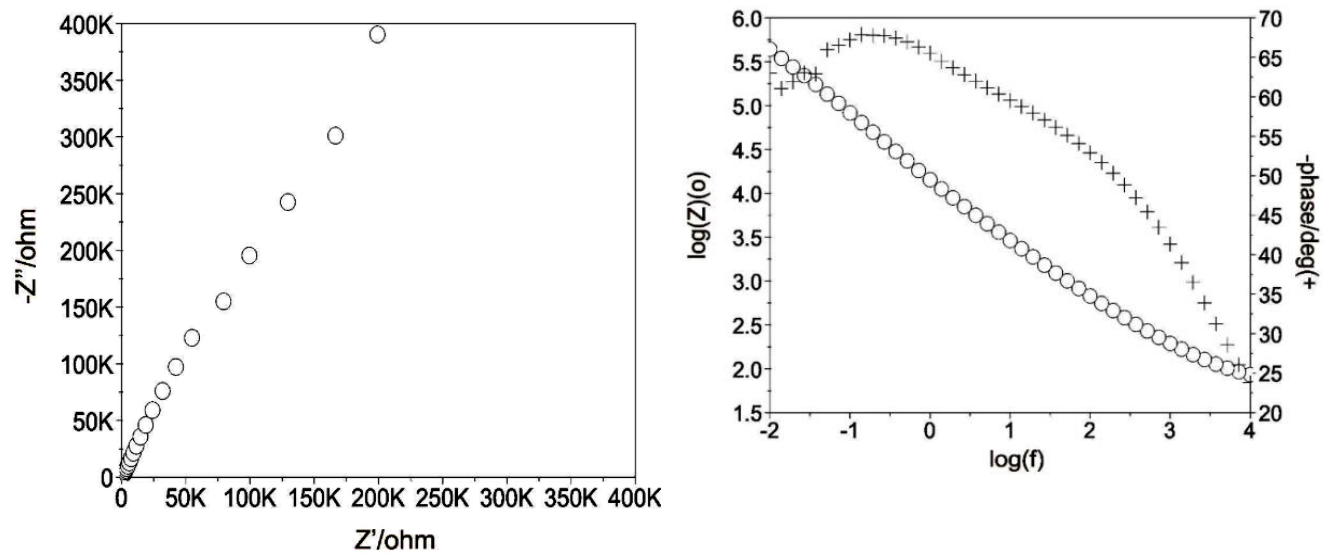

(d)

(e)

Figure 9. Cont. 


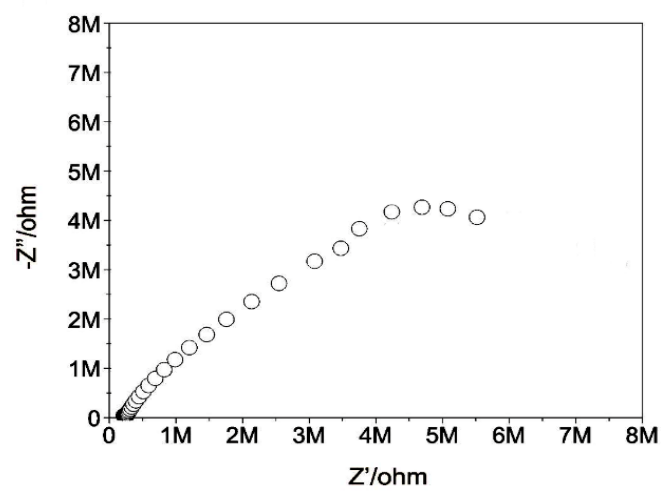

$(\mathbf{f})$

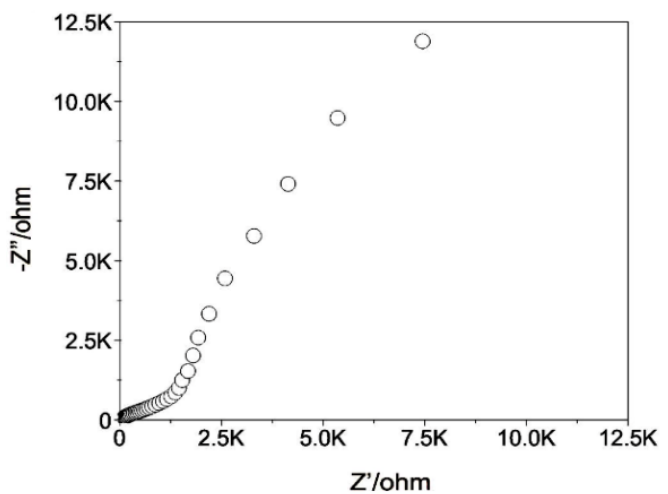

$(\mathrm{g})$

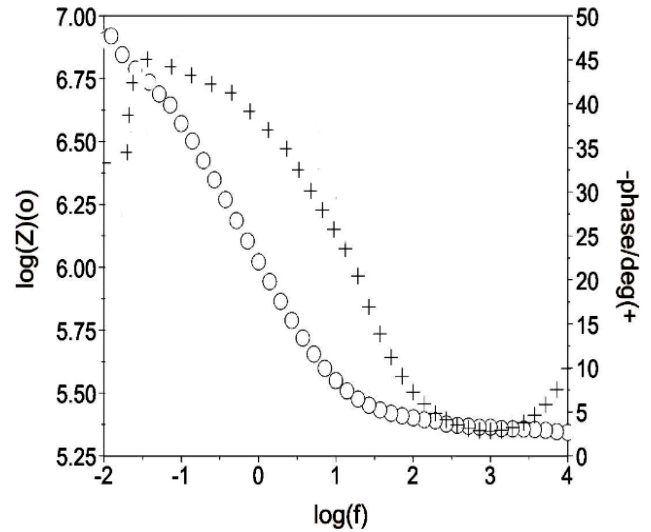

(g)

M5

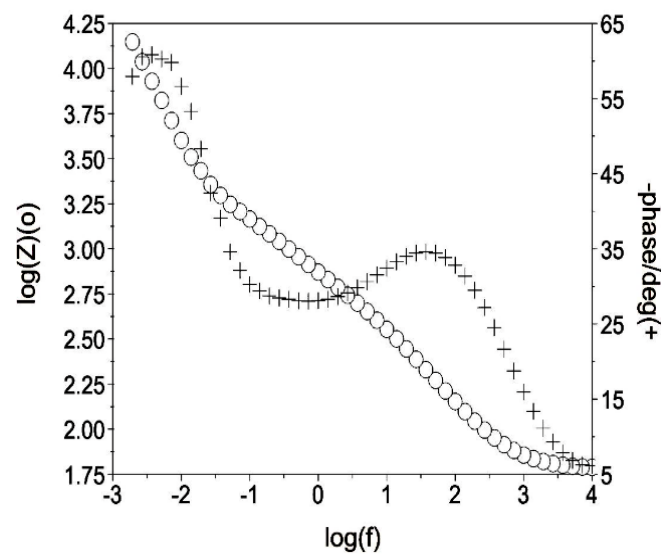

(h)

Figure 9. Examples of results of electrochemical impedance spectroscopy (EIS) test for M1 (a,c,e,g) Nyquist diagram; (b,d,f,h) Bode diagram.

The analysis of the impedance spectra of corrosive systems tested samples using Ringer's solution, the equivalent electrical system shown in Figure 10 was used. Based on this, the parameters of the electrical components of the replacement circuits describing the corrosion systems were determined-See Table 9. This method allowed the analysis and interpretation of processes and phenomena occurring at the interface: Tested samples - Ringer's solution. Impedance spectra (Figure 10) obtained for the analyzed samples were interpreted by comparison to a substitute electrical system, which indicates the occurrence of two sublayers: A compact internal and a porous external layer (two time constants visible on the graph), where $R_{S}$ is the resistance of electrolyte (Ringer solution), $\mathrm{R}_{\text {pore }}$-electrolyte resistance in the porous phase, $\mathrm{CPE}_{\text {pore }}$-capacity of the double layer (porous, surface), $\mathrm{R}_{\mathrm{ct}}$-resistance of the deposited coating (characterizes the electric charge transfer resistance at the boundary of phases: Grade II-surface layer-Ringer solution) and CPE $\mathrm{dl}_{\mathrm{dl}}$-capacity of the deposited coating, Figure 10. The use of two constant-phase elements in an electrical substitute circuit positively influenced the quality of fitting the experimentally determined curves. The mathematical impedance model of the above system is also presented in the Equation (3). 


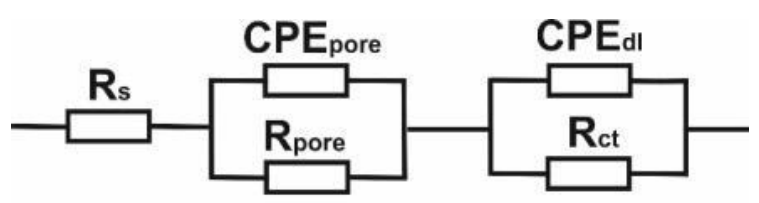

Figure 10. Electric substitute scheme.

Table 9. Results of EIS test.

\begin{tabular}{|c|c|c|c|c|c|c|c|c|c|}
\hline \multirow{2}{*}{ No. } & & \multirow{2}{*}{$\begin{array}{l}\text { E }_{\text {opcr, }} \\
{[\mathrm{mV}]}\end{array}$} & \multirow{2}{*}{$\begin{array}{c}\mathbf{R}_{\mathrm{s}} \\
{\left[\Omega \mathrm{cm}^{2}\right]}\end{array}$} & \multirow{2}{*}{$\begin{array}{c}R_{\text {pore }} \\
{\left[\Omega \mathrm{cm}^{2}\right]}\end{array}$} & \multicolumn{2}{|c|}{$\mathrm{CPE}_{\text {pore, }}[\mathrm{mV}]$} & \multirow{2}{*}{$\begin{array}{c}\mathbf{R}_{\mathrm{ct},} \\
{\left[\mathrm{k} \Omega \mathrm{cm}^{2}\right]}\end{array}$} & \multicolumn{2}{|l|}{$\mathrm{CPE}_{\mathrm{d} l},[\mathrm{mV}]$} \\
\hline & & & & & $\mathrm{Y},\left[\mathrm{k} \Omega \mathrm{cm}^{-\mathrm{m}} \mathrm{s}^{-\mathrm{n}}\right]$ & $\mathrm{n}_{1}$ & & $\mathrm{Y},\left[\Omega \mathrm{cm}^{-\mathrm{m}} \mathbf{s}^{-\mathrm{n}}\right]$ & $\mathrm{n}_{2}$ \\
\hline 1 & M1 & -257 & 40 & 40 & $0.8553 \times 10^{-5}$ & 0.9 & 4930 & $0.6732 \times 10^{-5}$ & 0.7 \\
\hline 2 & M2 & -257 & 55 & 619 & $0.7440 \times 10^{-6}$ & 0.9 & 4520 & $0.7616 \times 10^{-6}$ & 0.9 \\
\hline 3 & M3 & -257 & 54 & 592 & $0.7440 \times 10^{-6}$ & 0.6 & 10,255 & $0.1884 \times 10^{-5}$ & 0.9 \\
\hline 4 & M4 & +42 & 69 & 1 & $0.1258 \times 10^{-4}$ & 0.8 & 2494 & $0.1759 \times 10^{-4}$ & 0.8 \\
\hline 5 & M5 & -2 & 68 & 53 & $0.4426 \times 10^{-4}$ & 0.9 & 11,320 & $0.3157 \times 10^{-4}$ & 0.7 \\
\hline
\end{tabular}

$$
Z=R_{\mathrm{s}}+\frac{1}{\frac{1}{R_{\mathrm{p}}}+Y_{01}(j \omega)^{n_{1}}}+\frac{1}{\frac{1}{R_{\mathrm{ct}}}+Y_{02}(j \omega)^{n_{2}}}
$$

The fifth sample group M5 was characterized by high electrochemical stability, which was proved by relatively high value charge transfer resistance $R_{c t}$. The mean value of $R_{c t}$ parameters for M5 was $11,320 \mathrm{k} \Omega \mathrm{cm}^{2}$, which was similar to the value obtained for the M3 sample group, $10,254 \mathrm{k} \Omega \mathrm{cm}^{2}$.

The microscopic observations were also performed for all tested samples after the pitting corrosion test. Only for the samples with CrN coating M2 was the pitting corrosion observed (Figure 11). This means that the coating may not be a good protection against the environment.

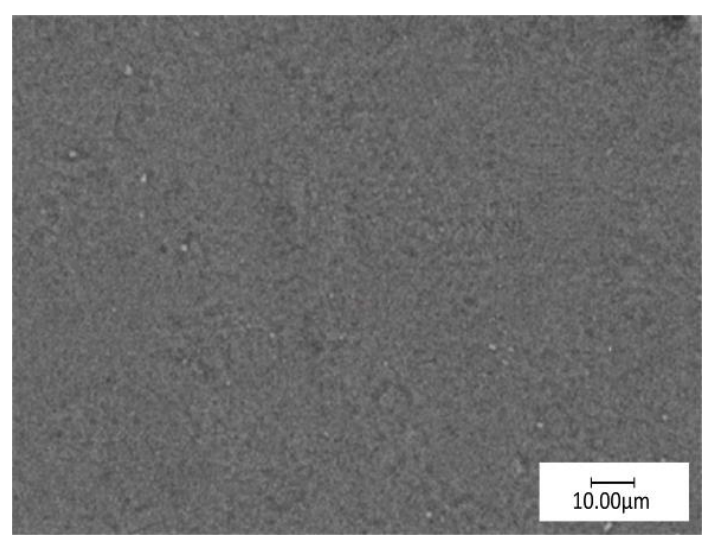

(a)

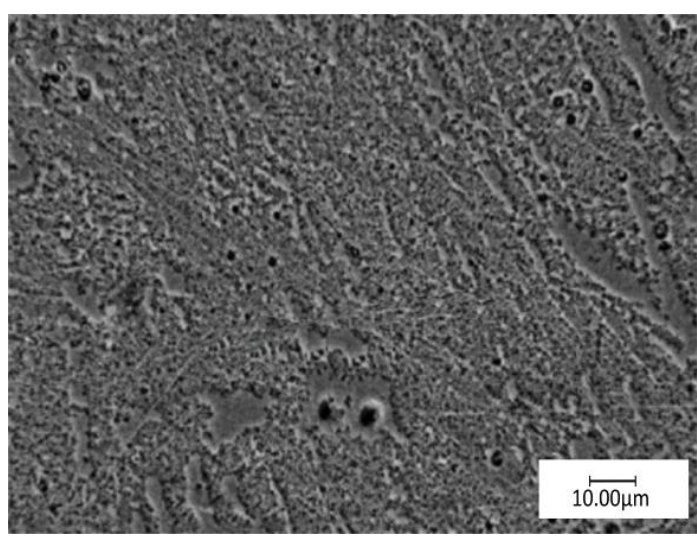

(b)

Figure 11. Examples of surface topography of M2 sample group (a) before; (b) after pitting corrosion test.

\subsection{Wear Test}

Based on the obtained results of wear test (Table 10) it can be concluded that the samples in initial state M1 and samples with CrN layer M2 were characterized by the lowest value of friction coefficient, and the mean value was approximately $\mu=0.54 \pm 0.06$ and $\mu=0.55 \pm 0.08$, respectively. The laser texturing for both PVD layer variants improved to the increased value of the friction coefficient. The highest values were measured for the samples with the TiN layer after surface texturing M5 and the mean value was $0.69 \pm 0.07$. 
Table 10. The results of the wear test.

\begin{tabular}{ccccc}
\hline No. & Name & $\boldsymbol{\mu}$ & Wear Volume, $[\mu \mathrm{m}]$ & W \\
\hline 1 & M1 & $0.54 \pm 0.06$ & $51,571 \pm 9184$ & $2.2 \times 10^{-16}$ \\
2 & M2 & $0.55 \pm 0.08$ & $19,174 \pm 1131$ & $7.7 \times 10^{-17}$ \\
3 & M3 & $0.62 \pm 0.6$ & $22,287 \pm 1063$ & $8.9 \times 10^{-17}$ \\
4 & M4 & $0.63 \pm 0.07$ & $19,247 \pm 1053$ & $7.4 \times 10^{-17}$ \\
5 & M5 & $0.69 \pm 0.07$ & $18,786 \pm 1088$ & $7.2 \times 10^{-17}$ \\
\hline
\end{tabular}

Based on the obtained time history of the friction coefficient for the M5 sample group, there is a running a sudden increase in the coefficient of friction is initially visible, after which the friction coefficient has reached a steady state (Figure 12a). Based on the obtained results of the measurements of the depth of wear, for both $\mathrm{CrN}$ and TiN coating as a result of friction, the coating was damaged and permanently removed from the surface of the tested samples at the place of contact of the rubbing pair of the tested surface of the counter-sample. However, in the case of sample M5, the TiN coating continued to break after $500 \mathrm{~s}$, where for the $\mathrm{CrN}$ coating the break occurred after about $125 \mathrm{~s}$ - That is according to the assumption since the thickness of the coatings are different. Based on the wear profile measurements the wear volumes were calculated. Based on the obtained results it can be concluded, that the surface modification, regardless of the type of the layer and laser texturing leads to reduced values of wear volume. Additionally, based on the wear coefficient calculated it can be concluded that the lowest volume was obtained for M5 sample group and the mean value was approximately $\mathrm{W}=7.2 \times 10^{-17}$. Examples of the results of the wear test for the M5 sample are presented in Figure $12 \mathrm{~b}$.

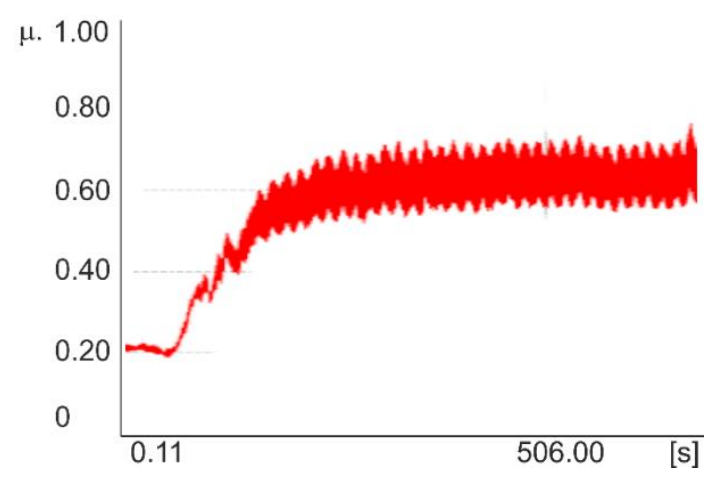

(a)

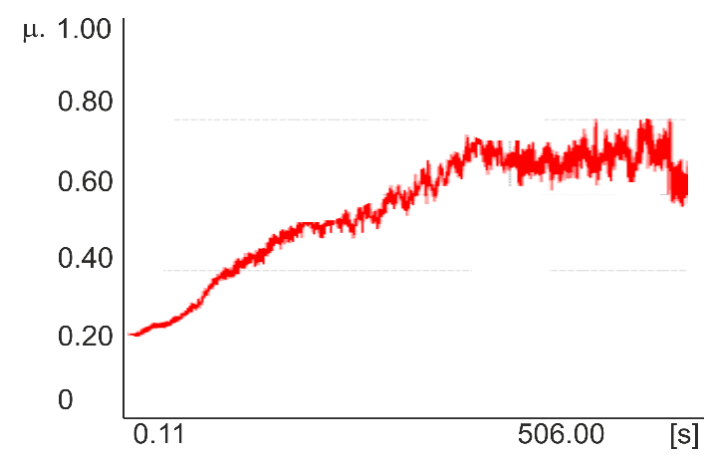

(c)

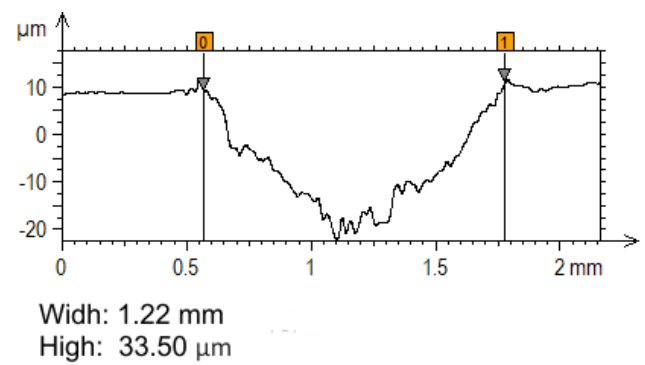

(b)

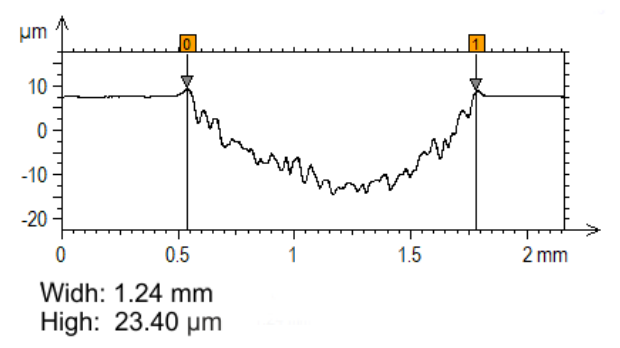

(d)

Figure 12. Examples of results of wear test for the M4 samples group: (a) diagram of coefficient friction changes; (b) wipe profile, and results of wear test for M5 samples (c) diagram of coefficient friction changes; (d) wipe profile. 


\section{Discussion}

For medical application, very important are the high quality of the surface of the materials and homogeneous structure. The surface microscopic observations of the samples in initial state (M1 samples group) are characterized by defect-free homogeneous structure. The pattern for the base material was typical of the pure titanium, and predominantly showed peaks associated with the $\alpha$-Ti phase (hexagonal cell), which is comparable to other results presented by Stwora et al. [42]. The surface of the samples after modification by PVD, independently of the type of the nitride layer was uniform and no spalling or discolorations were detected. During modification, agglomerations formed on the material surface and the surface quality of the degraded coating, which was also stated in the work of Tang et al. [54]. The XRD analysis, showed a face centered cubic cell of CrN pattern with (113) and (200) peaks for the M2 samples-similar results were obtained by Chen et al. [55]. The diffraction pattern show also reflections from body centered cubic Cr. The pattern for the M3 sample group is predominantly that of the face centered cubic cell of TiN phase and the strongest peak is located at (111) crystal plane, which is comparable to the results obtained by Nolan et al. [56]. As (111) crystal orientation represents a compact crystal plane, it indicates that the coating structure obtained at this temperature is denser. In the case of ablation with an ultrafast pico-second laser, the texturing material absorbs heat, which causes melt or evaporation. During the interaction between laser and material, the molten and evaporated parts solidify, resulting in sputtering accumulation on the unprocessed surface [57]. The microscopic observation of the laser surface texturing of the samples after modification by the PVD method showed a coarse ablated surface, where the edge of the groove appears to be continuous; only a few corrugated grooves with chunks of residues scattered inside the groove and the heat-affected zone on the treated surfaces have also been observed. In the position close to the edge of the hexagon there is a little accumulation of the molten matters, which leads to a convex structure $[27,58,59]$.

The micro- and nanoscale features of topography influence cellular biological interaction and interfere with macromolecules, which form conditioning films under human body physiological conditions. Ting et al. [60] has shown that the value of wetting angle of the pure titanium regardless of surface roughness was in the range from 70 to $90^{\circ}$, which is comparable to the obtained value for the M1 samples group $\left(\theta=78 \pm 10^{\circ}\right)$. Based on the results obtained, it can be concluded that surface modification by the PVD method lead to increased wettability of the surface. The higher values of the contact were obtained for the samples with CrN layer (M2) and TiN (M3) and the mean value was $\theta=98 \pm 8^{\circ}$ and $\theta=101 \pm 12^{\circ}$, respectively. For this case, the surface tension force leads to a minimization of the total surface energy of measuring the liquid drop in the effect of producing a spherical shape with a relatively high value of wetting angle. The value of the contact angle for the samples after laser texturing (M4 and M5) decreased, which can be associated with development of the surface topography and chemical heterogeneity, thus inducing deviations from an ideal surface. Due to increased surface area, there was an increased wettability of the textured surface against deionized water, and similar results were also obtained by Pfleging et al. [61]. After laser texturing, in the effect of the condensation of the molten material, some raised frames around the scanning path were formed. Based on the results obtained, it can be concluded that the formed frames cannot support the droplet of the water, and the droplet immersed into the texture, which is associated with the Wenzel state [44]. However, the values of wetting angle for both M4 and M5 are approximately $80^{\circ}$, which indicates a slight advantage of gravitational forces over surface tension forces. The different tendency of wetting angle between the distilled water and the diiodonomethane has been observed. The differences of the values are associated with their chemical character; the water is a polar and diiodonomethane is an apolar liquid, which differ in their vapour pressure at room temperature and the molecular volume [62]. On the weakly polar surface of the material, the lower values of the contact angles were measured for diiodomethane droplets-for all tested samples groups, the value of the contact angles measured using diiodomethane were similar and were in the range $44-51^{\circ}$ and higher compared to polar components. In recent years, it has been proven that the degree of microbial colonization depends not only on 
the surface quality of the implant, but also on the hydrophobicity of the microorganisms, which was pointed to by Loosdrecht et al. [63]. Based on the results presented by Kochkodan et al. [64] and Giaouris et al. [65], it can be concluded the more hydrophilic cells or bacterial adhere more strongly to hydrophilic surfaces, while hydrophobic microorganisms strongly adhere to hydrophobic surface. Additionally, Borecká-Melkusová and Bujdakova et al. [66], showed that the microorganisms in the effect of changes in environmental composition, such as temperature or compositions of nutrients, can switch between hydrophilic and hydrophobic phenotypes. For example, the main driving force for adhesion of pathogens S. Aurerus and S. epidermidis is hydrophobicity. In addition, it was recorded that surfaces become more hydrophilic with higher values of the polar component of SFE [64] which was also obtained in this work for the surface of the tested samples. The samples with the highest value of the contact angle, exhibit a strongly affinity to apolar components of SFE. The SFE is a measure for the adhesiveness of the surface. For the material in initial state M1, the higher value of the SFE was recorded $\left(\gamma_{S}=44 \mathrm{~mJ} / \mathrm{m}^{2}\right)$. Apart from microbiological properties, the higher value of SFE of substrate material can affect the greater strength of PVD layers adhesion to the substrate. Additionally, the high value of SFE of the coatings can also affect the increase of wear resistance. It is important, because the main limitation of the use of titanium in human body is the aggressive environment present in vivo as well as low tribological properties and low resistance to the pitting corrosion. Based on the results obtained it can be concluded that, the laser texturing lead to improvement of corrosion resistance and it is possibly due presence of oxide. A detailed analysis of polarization behavior shows that the transpassivation potential increases from $1088 \pm 87 \mathrm{mV}$ to $1104 \pm 95$ for the M4 samples group, and from $2572 \pm 102 \mathrm{mV}$ to $3052 \pm 143 \mathrm{mV}$ for the M5 samples group. Similarly, the improvements in corrosion resistance of excimer laser surface treated Ti-6Al4V alloy was also reported by Yue et al. [67] and Kumari et al. [68]. The oxide layers, formed as a result of laser texturing in contact with corrosive environments, were characterized by greater stability and provides better protection against surface digestion. In the aspect of the hybrid surface modification and their impact on the physicochemical properties, the results obtained for the pure titanium and for the Ti-6Al-4V alloy may be similar. For both materials, the most commonly identified layer is $\mathrm{TiO}_{2}$, showing two different crystalline phases, anatase and rutile. For the Grade V, the passive layer may consist with a small amount of $\mathrm{Al}_{2} \mathrm{O}_{3}$ oxides [69]. Only for the samples in initial state, the existence of the breakdown potential has been stated. However, the microscopic observation didn't showed the pitting. Additionally, surface corrosion after the potentiodynamic test was visible for samples with $\mathrm{CrN}$ coating (M2 samples group). It should be noted that the mean value of the breakdown potential for M1 samples group $\left(\mathrm{E}_{\mathrm{b}}=\right.$ $1709 \pm 87 \mathrm{mV}$ ) was higher in comparison to the mean value of the transpassivation potential of M2 samples group $\left(E_{\mathrm{tr}}=1088 \pm 87 \mathrm{mV}\right)$, which showed that the reconstruction of the passive layer on the surface of the M2 samples group began earlier than changes in the surface of M1 samples. Additionally, that the samples with the higher value of the contact angle and low value of the polar component of the SFE were characterized by higher corrosion resistance and better wear resistance- the samples with TiN layer after laser texturing M5 are characterized by the best pitting corrosion resistance-and the highest value of transpassivation potential $\mathrm{E}_{\mathrm{tr}}=3052 \pm 143 \mathrm{mV}$ and the highest value of the charge transfer resistance $R_{c t}=1132 \mathrm{k} \Omega \mathrm{cm}^{2}$ were obtained. For all tested samples, the EIS test indicates the occurrence of two sublayers: a compact internal and a porous external layer. The double layer is a good protection against a corrosive environment. The value of the resistance of charge transfer across the phase boundary-passive layer-of the Ringer's rosettes informs about the amount of ions released from the surface of the tested material.

Additionally, the M5 sample group was characterized by the highest wear resistance. In case of the samples with $\mathrm{CrN}$ layer, texturing improved the decreased physicochemical properties, which can be associated with the oxide layers formed on the surface during laser investigation. 


\section{Conclusions}

The value of the contact angle increases as an effect of the surface modification by the PVD method. However, for the samples after laser texturing, decrease of the wetting angle, as a result of surface development, were recorded. The higher value of the contact angle and surface free energy lead to better corrosion and wear resistance. As a result, the balance between the required biological reaction, elimination of bacterial adhesion and increase of corrosion and wear resistance needs to be considered. The samples with TiN layer after texturing M5 were characterized by the most favorable properties-a high value of the contact angle (near to hydrophobic character of the surface), low surface development, the best pitting corrosion resistance, and the highest value of the friction coefficient. In the future, in vitro biological studies should be carried out to confirm the relationship between the chemical character of the surface treatment and cellular response and bacterial adhesion.

Author Contributions: Conceptualization, A.W. and M.A.; methodology, A.W. and W.W.; software, A.W.; validation, G.C., M.A. and W.W.; formal analysis, M.B.; investigation, A.W.; resources, A.W.; data curation, A.W.; writing — original draft preparation, A.W and W.W.; writing—review and editing, A.W.; visualization, A.W. and O.B.; supervision, M.A., G.C. and W.W.; project administration, M.A.; funding acquisition, A.W. and M.B. All authors have read and agreed to the published version of the manuscript.

Funding: This research was financed by Silesian University of Technology through "Scholarship for co-financing the commencement of scientific activity in a new research area within the priority specializations of the Silesian University of Technology" - Impact of hybrid surface modification of selected biomedical materials on their properties and biofunctionality.

Conflicts of Interest: The authors declare no conflict of interest.

\section{References}

1. Elias, C.N.; Fernandes, D.J.; De Souza, F.M.; Monteiro, E.D.S.; De Biasi, R.S. Mechanical and clinical properties of titanium and titanium-based alloys (Ti G2, Ti G4 cold worked nanostructured and Ti G5) for biomedical applications. J. Mater. Res. Technol. 2019, 8, 1060-1069. [CrossRef]

2. Ivlev, I.; Vacek, J.; Kneppo, P. Multi-criteria decision analysis for supporting the selection of medical devices under uncertainty. Eur. J. Oper. Res. 2015, 247, 216-228. [CrossRef]

3. Bazaka, K.; Jacob, M.V. Implantable devices: Issues and challenges. Electronics 2012, 2, 1-34. [CrossRef]

4. Mavros, N.; Larimian, T.; Esqivel, J.; Gupta, R.K.; Contieri, R.; Borkar, T. Spark plasma sintering of low modulus titanium-niobium-tantalum-zirconium (TNTZ) alloy for biomedical applications. Mater. Des. 2019, 183, 108163. [CrossRef]

5. Ramezannejad, A.; Xu, W.; Xiao, W.L.; Fox, K.; Liang, D.; Qian, M. New insights into nickel-free superelastic titanium alloys for biomedical applications. Curr. Opin. Solid State Mater. Sci. 2019, 23, 100783. [CrossRef]

6. Attar, H.; Bermingham, M.J.; Ehtemam-Haghighi, S.; Dehghan-Manshadi, A.; Kent, D.; Dargusch, M.S. Evaluation of the mechanical and wear properties of titanium produced by three different additive manufacturing methods for biomedical application. Mater. Sci. Eng. A 2019, 760, 339-345. [CrossRef]

7. Barman, A.; Das, M. Nano-finishing of bio-titanium alloy to generate different surface morphologies by changing magnetorheological polishing fluid compositions. Precis. Eng. 2018, 51, 145-152. [CrossRef]

8. Ozdemir, Z.; Ozdemir, A.; Basim, G.B. Application of chemical mechanical polishing process on titanium based implants. Mater. Sci. Eng. C 2016, 68, 383-396. [CrossRef] [PubMed]

9. Rao, S.; Astaneh, S.H.; Villanueva, J.; Silva, F.; Takoudis, C.; Bijukumar, D.; Souza, J.C.M.; Mathew, M.T. Physicochemical and in-vitro biological analysis of bio-functionalized titanium samples in a protein-rich medium. J. Mech. Behav. Biomed. Mater. 2019, 96, 152-164. [CrossRef] [PubMed]

10. Hryniewicz, T.; Rokicki, R.; Rokosz, K. Corrosion and surface characterization of titanium biomaterial after magnetoelectropolishing. Surf. Coat. Technol. 2009, 203, 1508-1515. [CrossRef]

11. Raikar, S.; Talukdar, P.; Kumari, S.; Panda, S.K.; Oommen, V.M.; Prasad, A. Factors affecting the survival rate of dental implants: A retrospective study. J. Int. Soc. Prev. Community Dent. 2017, 7, 351-355. [CrossRef] [PubMed]

12. Salem, K.H.; Lindner, N.; Tingart, M.; Elmoghazy, A.D. Severe metallosis-related osteolysis as a cause of failure after total knee replacement. J. Clin. Orthop. Trauma. 2020, 11, 165-170. [CrossRef] [PubMed] 
13. Magone, K.; Luckenbill, D.; Goswami, T. Metal ions as inflammatory initiators of osteolysis. Arch. Orthop. Trauma Surg. 2015, 135, 683-695. [CrossRef] [PubMed]

14. Veiko, V.P.; Odintsova, G.V.; Gazizova, M.Y.; Karlagina, Y.Y.; Manokhin, S.S.; Yatsuk, R.M.; Vasilkov, S.D.; Kolobov, Y.R. The influence of laser micro- and nanostructuring on the wear resistance of Grade-2 titanium surface. Laser Phys. 2018, 28, 086002. [CrossRef]

15. Babis, G.C.; Stavropoulos, N.A.; Sasalos, G.; Ochsenkuehn-Petropoulou, M.; Megas, P. Metallosis and elevated serum levels of tantalum following failed revision hip arthroplasty-A case report. Acta Orthop. 2014, 85, 677-680. [CrossRef]

16. Prasad, K.; Bazaka, O.; Chua, M.; Rochford, M.; Fedrick, L.; Spoor, J.; Symes, R.; Tieppo, M.; Collins, C.; Markwll, D.; et al. Metallic biomaterials: Current challenges and opportunities. Materials 2017, 10, 884. [CrossRef]

17. Souza, J.C.M.; Barbosa, S.L.; Ariza, E.A.; Henriques, M.; Teughels, W.; Ponthiaux, P.; Celis, J.P.; Rocha, L.A. How do titanium and Ti6Al4V corrode in fluoridated medium as found in the oral cavity? An in vitro study. Mater. Sci. Eng. C 2015, 47, 384-393. [CrossRef]

18. Çelik, I. Influence of CrN Coating on Electrochemical Behavior of Plasma Nitrided Pure Titanium in Bio-simulated Environment. J. Bionic Eng. 2016, 13, 150-155. [CrossRef]

19. Zhao, X.; Liu, H.; Li, S.; Wang, X.; Sheng, Y.; Zhang, P.; Li, W. Combined effect of TiN coating and surface texture on corrosion-wear behavior of selective laser melted CP-titanium in simulated body fluid. J. Alloys Compd. 2020, 816, 152667. [CrossRef]

20. Pedrosa, P.; Alves, E.; Barradas, N.P.; Fiedler, P.; Haueisen, J.; Vaz, F.; Fonseca, C. TiN x coated polycarbonate for bio-electrode applications. Corros. Sci. 2012, 56, 49-57. [CrossRef]

21. Rupp, F.; Scheideler, L.; Eichler, M.; Geis-Gerstorfer, J. Wetting behavior of dental implants. Int. J. Oral Maxillofac. Implant. 2011, 26, 1256-1266.

22. Gittens, R.A.; Olivares-Navarrete, R.; Cheng, A.; Anderson, D.M.; McLachlan, T.; Stephan, I.; Geis-Gerstorfer, J.; Sandhage, K.H.; Fedorov, A.G.; Rupp, F.; et al. The roles of titanium surface micro/nanotopography and wettability on the differential response of human osteoblast lineage cells. Acta Biomater. 2013, 9, 6268-6277. [CrossRef]

23. Wennerberg, A.; Albrektsson, T. Effects of titanium surface topography on bone integration: A systematic review. Clin. Oral Implant. Res. 2009, 20, 172-184. [CrossRef]

24. Erdemir, A. Review of engineered tribological interfaces for improved boundary lubrication. Tribol. Int. 2005, 38, 249-256. [CrossRef]

25. Fage, S.W.; Muris, J.; Jakobsen, S.S.; Thyssen, J.P. Titanium: A review on exposure, release, penetration, allergy, epidemiology, and clinical reactivity. Contact Dermat. 2016, 74, 323-345. [CrossRef]

26. Etsion, I. Improving tribological performance of mechanical components by laser surface texturing. Tribol. Lett. 2004, 17, 733-737. [CrossRef]

27. Grabowski, A.; Sozańska, M.; Adamiak, M.; Kępińska, M.; Florian, T. Laser surface texturing of Ti6Al4V alloy, stainless steel and aluminium silicon alloy. Appl. Surf. Sci. 2018, 461, 117-123. [CrossRef]

28. Quirynen, M.; Al-Nawas, B.; Meijer, H.J.A.; Razavi, A.; Reichert, T.E.; Schimmel, M.; Storelli, S.; Romeo, E.; Bräuer, I.; Castro-Laza, J. Small-diameter titanium Grade IV and titanium-zirconium implants in edentulous mandibles: Three-year results from a double-blind, randomized controlled trial. Clin. Oral Implants Res. 2015, 26, 831-840. [CrossRef] [PubMed]

29. Cordeiro, J.M.; Barão, V.A.R. Is there scientific evidence favoring the substitution of commercially pure titanium with titanium alloys for the manufacture of dental implants? Mater. Sci. Eng. C 2017, 71, 1201-1215. [CrossRef] [PubMed]

30. Mareci, D.; Bocanu, C.; Nemtoi, G.; Aelenei, D. Electrochemical behaviour of titanium alloys in artificial saliva. J. Serb. Chem. Soc. 2005, 70, 891-897. [CrossRef]

31. Hong, M.-H.; Min, B.; Kwon, T.-Y. Fabricating High-Quality 3D-Printed Alloys for Dental Applications. Appl. Sci. 2017, 7, 710. [CrossRef]

32. Cosma, C.; Kessler, J.; Gebhardt, A.; Campbell, I.; Balc, N. Improving the mechanical strength of dental applications and lattice structures SLM processed. Materials 2020, 13, 905. [CrossRef] [PubMed]

33. Vlacic-Zischke, J.; Hamlet, S.M.; Friis, T.; Tonetti, M.S.; Ivanovski, S. The influence of surface microroughness and hydrophilicity of titanium on the up-regulation of TGF $\beta / B M P$ signalling in osteoblasts. Biomaterials 2011, 32, 665-671. [CrossRef] [PubMed] 
34. Olivares-Navarrete, R.; Hyzy, S.L.; Hutton, D.L.; Erdman, C.P.; Wieland, M.; Boyan, B.D.; Schwartz, Z. Direct and indirect effects of microstructured titanium substrates on the induction of mesenchymal stem cell differentiation towards the osteoblast lineage. Biomaterials 2010, 31, 2728-2735. [CrossRef] [PubMed]

35. Sotniczuk, A.; Heise, S.; Topolski, K.; Garbacz, H.; Boccaccini, A.R. Chitosan/bioactive glass coatings as a protective layer against corrosion of nanocrystalline titanium under simulated inflammation. Mater. Lett. 2020, 264, 127284. [CrossRef]

36. Liu, J.; Zhang, L.; Mu, X.; Zhang, P. Studies of electrochemical corrosion of low alloy steel under epoxy coating exposed to natural seawater using the WBE and EIS techniques. Prog. Org. Coat. 2017, 111, 315-321. [CrossRef]

37. Shanaghi, A.; Chu, P.K. Investigation of corrosion mechanism of NiTi modified by carbon plasma immersion ion implantation (C-PIII) by electrochemical impedance spectroscopy. J. Alloys Compd. 2019, 790, 1067-1075. [CrossRef]

38. Ribeiro, D.V.; Abrantes, J.C.C. Application of electrochemical impedance spectroscopy (EIS) to monitor the corrosion of reinforced concrete: A new approach. Constr. Build. Mater. 2016, 111, 98-104. [CrossRef]

39. Liverani, E.; Toschi, S.; Ceschini, L.; Fortunato, A. Effect of selective laser melting (SLM) process parameters on microstructure and mechanical properties of 316L austenitic stainless steel. J. Mater. Process. Technol. 2017, 249, 255-263. [CrossRef]

40. Guo, P.; Zou, B.; Huang, C.; Gao, H. Study on microstructure, mechanical properties and machinability of efficiently additive manufactured AISI 316L stainless steel by high-power direct laser deposition. J. Mater. Process. Technol. 2017, 240, 12-22. [CrossRef]

41. Gao, W.; Zhang, Y.; Ramanujan, D.; Ramani, K.; Chen, Y.; Williams, C.B.; Wang, C.C.L.; Shin, Y.C.; Zhang, S.; Zavattieri, P.D. The status, challenges, and future of additive manufacturing in engineering. CAD Comput. Aided Des. 2015, 69, 65-89. [CrossRef]

42. Stwora, A.; Skrabalak, G. Influence of selected parameters of Selective Laser Sintering process on properties of sintered materials Manufacturing and processing. Mater. Sci. 2013, 61, 375-380.

43. Ziębowicz, A.; Woźniak, A.; Ziębowicz, B.; Adamiak, M.; Boryło, P. Microstructure and properties of CoCr alloys used in prosthetics procedure. Arch. Mater. Sci. Eng. 2018, 89, 20-26. [CrossRef]

44. Wang, Y.; Ke, C.; Wu, T.; Zhao, X.; Wang, R. Nanosecond laser texturing with hexagonal honeycomb micro-structure on Titanium for improved wettability and optical properties. Optik (Stuttg) 2019, 192, 162953. [CrossRef]

45. Yu, Z.; Yang, G.; Zhang, W.; Hu, J. Investigating the effect of picosecond laser texturing on microstructure and biofunctionalization of titanium alloy. J. Mater. Process. Technol. 2018, 255, 129-136. [CrossRef]

46. Nuckowski, P.M.; Wróbel, T. The influence of variable parameters of horizontal continuous casting on the structure of $\mathrm{AlCu}_{4} \mathrm{MgSi}$ alloy ingots. Arch. Foundry Eng. 2018, 18, 196-202. [CrossRef]

47. Nuckowski, P.M. Texture and residual stresses in the cusn 6 alloy subjected to intense plastic deformation. Arch. Metall. Mater. 2018, 63, 241-245. [CrossRef]

48. Ziębowicz, A.; Woźniak, A.; Ziębowicz, B. The Influence of Technology on the Physicochemical and Electrochemical Properties of the Prosthetic Materials; Springer: Berlin, Germany, 2018; pp. 349-357.

49. Firlik, S. Comparison of methods for the surface free energy determination of polimeric layers aligning liquid crystals (in polish). Chemik 2010, 64, 238-245.

50. ISO 3685-Tools Life Testing with Singer-Point Turning Tools; PN-EN ISO 10993-15:2019. Biological evaluation of medical devices. Part 15: Identification and quantification of degradation products from metals and alloys; International Organization for Standardization: Geneva, Switzerland, 1993.

51. Amado, J.M.; Rodríguez, A.; Montero, J.N.; Tobar, M.J.; Yáñez, A. A comparison of laser deposition of commercially pure titanium using gas atomized or Ti sponge powders. Surf. Coat. Technol. 2019, 374, $253-263$. [CrossRef]

52. Giannelli, M.; Bani, D.; Tani, A.; Materassi, F.; Chellini, F.; Sassoli, C. Effects of an Erbium:Yttrium-Aluminum-Garnet Laser and Ultrasonic Scaler on Titanium Dioxide-Coated Titanium Surfaces Contaminated With Subgingival Plaque: An In Vitro Study to Assess Post-Treatment Biocompatibility With Osteogenic Cells. J. Periodontol. 2017, 88, 1211-1220. [CrossRef]

53. Li, K.; Yao, W.; Xie, Y.; Zhang, J.; Li, B.; Wan, Z.; Zhang, Z.; Lu, L.; Tang, Y. A strongly hydrophobic and serum-repelling surface composed of $\mathrm{CrN}$ films deposited on laser-patterned microstructures that was optimized with an orthogonal experiment. Surf. Coat. Technol. 2020, 391, 125708. [CrossRef] 
54. Tang, D.; Chen, H.; Xiao, W.; Deng, H.; Zou, S.; Ren, Y.; Lei, M.; Zhou, X. Substrate bias effects on mechanical properties and high temperature oxidation performance of sputtered TiN-coated Zr-4. J. Nucl. Mater. 2019, 524, 330-339. [CrossRef]

55. Chen, Y.; Wang, S.; Hao, Y.; Pu, J.; Jiang, X.; Huang, L.F.; Wang, L. Friction and Wear Behavior of CrN Coating on 316L Stainless Steel in Liquid Sodium at Elevated Temperature. Tribol. Int. 2020, 143, 106079. [CrossRef]

56. Nolan, D.; Huang, S.W.; Leskovsek, V.; Braun, S. Sliding wear of titanium nitride thin films deposited on Ti-6Al-4V alloy by PVD and plasma nitriding processes. Surf. Coat. Technol. 2006, 200, 5698-5705. [CrossRef]

57. Cai, Y.; Luo, X.; Maclean, M.; Qin, Y.; Duxbury, M.; Ding, F. A single-step fabrication approach for development of antimicrobial surfaces. J. Mater. Process. Technol. 2019, 271, 249-260. [CrossRef]

58. Raun, A.; Saklayen, N.; Zgrabik, C.; Shen, W.; Madrid, M.; Huber, M.; Hu, E.; Mazur, E. A comparison of inverted and upright laser-activated titanium nitride micropyramids for intracellular delivery. Sci. Rep. 2018, 8, 1-9. [CrossRef]

59. Voevodin, A.A.; Zabinski, J.S. Laser surface texturing for adaptive solid lubrication. Wear 2006, 261, 1285-1292. [CrossRef]

60. Ma, T.; Ge, X.; Zhang, Y.; Lin, Y. Effect of Titanium Surface Modifications of Dental Implants on Rapid Osseointegration. In Interface Oral Health Science 2016; Springer: Singapore, 2017; pp. 247-256.

61. Pfleging, W.; Kumari, R.; Besser, H.; Scharnweber, T.; Majumdar, J.D. Laser surface textured titanium alloy (Ti-6Al-4V): Part 1-Surface characterization. Appl. Surf. Sci. 2015, 355, 104-111. [CrossRef]

62. Chibowski, E.; Jurak, M. Comparison of contact angle hysteresis of different probe liquids on the same solid surface. Colloid Polym. Sci. 2013, 291, 391-399. [CrossRef]

63. Van Loosdrecht, W.; Mark, C.M.; Norde, W.; Zehnder, A.J.B. Physical Chemical Description of Bacterial Adhesion. J. Biomater. Appl. 1990, 5, 91-106. [CrossRef]

64. Kochkodan, V.; Tsarenko, S.; Potapchenko, N.; Kosinova, V.; Goncharuk, V. Adhesion of microorganisms to polymer membranes: A photobactericidal effect of surface treatment with $\mathrm{TiO}_{2}$. Desalination 2008, 220, 380-385. [CrossRef]

65. Giaouris, E.; Chapot-Chartier, M.P.; Briandet, R. Surface physicochemical analysis of natural Lactococcus lactis strains reveals the existence of hydrophobic and low charged strains with altered adhesive properties. Int. J. Food Microbiol. 2009, 131, 2-9. [CrossRef]

66. Borecká-Melkusová, S.; Bujdáková, H. Variation of cell surface hydrophobicity and biofilm formation among genotypes of Candida albicans and Candida dubliniensis under antifungal treatment. Can. J. Microbiol. 2008, 54, 718-724. [CrossRef] [PubMed]

67. Yue, T.M.; Cheung, T.M.; Man, H.C. Effects of laser surface treatment on the corrosion properties of Ti-6Al-4V alloy in Hank's solution. J. Mater. Sci. Lett. 2000, 19, 205-208. [CrossRef]

68. Kumari, R.; Scharnweber, T.; Pfleging, W.; Besser, H.; Majumdar, J.D. Laser surface textured titanium alloy (Ti-6Al-4V)-Part II-Studies on bio-compatibility. Appl. Surf. Sci. 2015, 357, 750-758. [CrossRef]

69. Yang, B.; Uchida, M.; Kim, H.M.; Zhang, X.; Kokubo, T. Preparation of bioactive titanium metal via anodic oxidation treatment. Biomaterials 2004, 25, 1003-1010. [CrossRef]

(C) 2020 by the authors. Licensee MDPI, Basel, Switzerland. This article is an open access article distributed under the terms and conditions of the Creative Commons Attribution (CC BY) license (http://creativecommons.org/licenses/by/4.0/). 